\title{
Macrophage Heterogeneity and Plasticity: Impact of Macrophage Biomarkers on Atherosclerosis
}

\author{
Joselyn Rojas, ${ }^{1,2}$ Juan Salazar, ${ }^{1}$ María Sofía Martínez, ${ }^{1}$ Jim Palmar, ${ }^{1}$ Jordan Bautista, ${ }^{1}$ \\ Mervin Chávez-Castillo, ${ }^{1}$ Alexis Gómez, ${ }^{1}$ and Valmore Bermúdez ${ }^{1}$ \\ ${ }^{1}$ Endocrine and Metabolic Diseases Research Center, School of Medicine, University of Zulia, Maracaibo 4004, Venezuela \\ ${ }^{2}$ Endocrinology Department, Maracaibo University Hospital, Maracaibo 4004, Venezuela
}

Correspondence should be addressed to Joselyn Rojas; rojas.joselyn@gmail.com

Received 15 June 2015; Accepted 9 September 2015

Academic Editor: Alexander Szalai

Copyright (C) 2015 Joselyn Rojas et al. This is an open access article distributed under the Creative Commons Attribution License, which permits unrestricted use, distribution, and reproduction in any medium, provided the original work is properly cited.

Cardiovascular disease (CVD) is a global epidemic, currently representing the worldwide leading cause of morbidity and mortality. Atherosclerosis is the fundamental pathophysiologic component of CVD, where the immune system plays an essential role. Monocytes and macrophages are key mediators in this aspect: due to their heterogeneity and plasticity, these cells may act as either pro- or anti-inflammatory mediators. Indeed, monocytes may develop heterogeneous functional phenotypes depending on the predominating pro- or anti-inflammatory microenvironment within the lesion, resulting in classic, intermediate, and nonclassic monocytes, each with strikingly differing features. Similarly, macrophages may also adopt heterogeneous profiles being mainly M1 and M2, the former showing a proinflammatory profile while the latter demonstrates anti-inflammatory traits; they are further subdivided in several subtypes with more specialized functions. Furthermore, macrophages may display plasticity by dynamically shifting between phenotypes in response to specific signals. Each of these distinct cell profiles is associated with diverse biomarkers which may be exploited for therapeutic intervention, including IL-10, IL-13, PPAR- $\gamma$, LXR, NLRP3 inflammasomes, and microRNAs. Direct modulation of the molecular pathways concerning these potential macrophage-related targets represents a promising field for new therapeutic alternatives in atherosclerosis and CVD.

\section{Introduction}

Cardiovascular disease (CVD) is currently recognized as the leading cause of morbidity and mortality in the adult population worldwide, with an estimated projection of 23.3 million yearly deceases attributable to these disorders by the year $2030[1,2]$. Data from our country reflect this global trend, with CVD being responsible for $20.9 \%$ of total mortality in Venezuela [3]. This surge in cardiovascular morbidity and mortality has been associated with increased prevalence of cardiometabolic risk factors and ineffective preventive strategies in primary care and public health management [4]. The severe epidemiologic and socioeconomic implications of CVD have propelled increased scientific interest into its pathophysiology, particularly atherosclerosis. Although multiple risk factors intervene in this process, recent findings suggest immunologic phenomena may play key roles in its evolution [5].
As part of the innate immune system, monocytes actively participate in the development of atherosclerosis by infiltrating the subendothelium in vascular walls. This process is facilitated by endothelial dysfunction, which is in turn propitiated by various cardiovascular risk factors [6]. Dysfunctional endothelium releases proinflammatory cytokines, such as Interleukin-6 (IL-6) and tumor necrosis factor- $\alpha$ (TNF- $\alpha$ ), and growth factors and expresses multiple cell adhesion molecules which allow recruitment and adhesion of monocytes to vessel walls, promoting their differentiation to activated macrophages capable of phagocytizing oxidized low-density lipoprotein (oxLDL) present in the subendothelium $[7,8]$.

This cellular differentiation may yield several distinct subtypes of macrophages in response to numerous microenvironmental signals modulating genomic expression in these cells [9]. This variable outcome has originated the concepts 


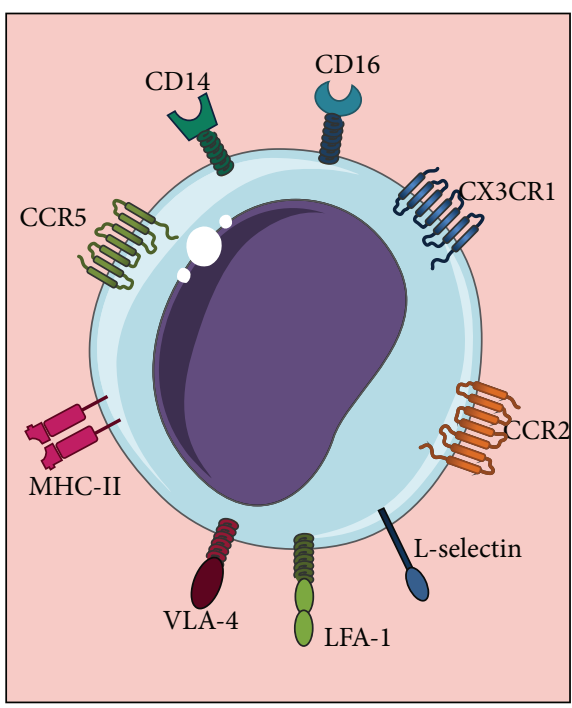

(a)

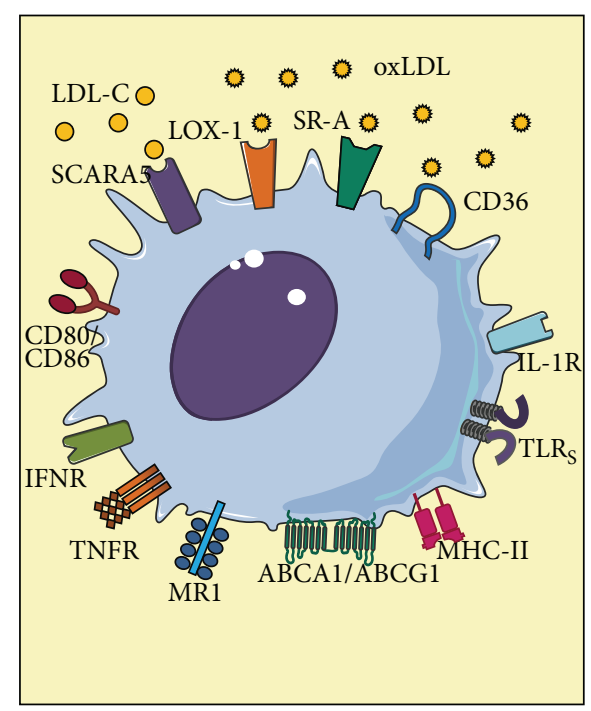

(b)

FIGURE 1: Features of monocytes and macrophages. (a) Classic monocyte. (b) Classic macrophage. Both classic monocytes and classic macrophages play essential roles in innate immune responses, expressing an ample variety of receptors that modulate their activation.

of monocyte and macrophage "heterogeneity" and "plasticity," alluding to their ability to specialize into and switch between distinct functional phenotypes in the presence of different environmental cues, including cytokines, microbial products, oxLDL, among others [10]. These properties appear promising regarding their potential as therapeutic targets in CVD, as they may allow attenuation of the proinflammatory milieu in atherosclerotic lesions [11]. This review discusses the molecular basis of monocyte and macrophage heterogeneity and plasticity and their implications for future clinical intervention.

\section{Monocyte Heterogeneity}

Monocytes stem from a myeloid precursor in the bone marrow, from where they are released into circulation, showing a relatively short half-life (1-3 days in humans) and a strong ability to adhere to the vascular endothelium and penetrate tissues in response to endothelial and subendothelial signals [12]. Following extravasation, monocytes localize to the subendothelium, where they may differentiate into distinct subtypes of macrophages, supported by several growth factors, mainly Macrophage Colony-Stimulating Factor (MCSF) [13] and Granulocyte-Macrophage Colony-Stimulating Factor (GM-CSF) [14], Figure 1.

Prior to differentiation, monocytes may show a range of distinct phenotypes according to the differential expression of specific cell surface markers [32], which are subject to environmental modulation. These markers include the Lipopolysaccharide (LPS) receptor antigen (CD14), present in almost all monocytes, and the $\operatorname{IgG~Fc~} \gamma$ receptor (CD16), expressed only in select groups of these cells [32]. Monocytes may be categorized in 3 subpopulations according to the presence of these components: "classic" monocytes $\left[\mathrm{CD} 14^{++} \mathrm{CD} 16^{-}\right]$, "intermediate" monocytes $\left[\mathrm{CD} 14^{++} \mathrm{CD} 16^{+}\right]$, and "nonclassic" monocytes $\left[\mathrm{CD} 14^{+} \mathrm{CD} 6^{++}\right][33,34]$. Each of these types has been reported to exhibit significant differences regarding expression of cell adhesion molecules and chemokine receptors, both of which are pivotal for adhesion and recruitment to the dysfunctional endothelium [35], Figure 2.

Classic monocytes $\left[\mathrm{CD} 14^{++} \mathrm{CD}^{-}{ }^{-}\right.$] constitute $80-95 \%$ of total circulating monocytes and primarily act as phagocytes, boasting strong peroxidase activity and predominantly releasing Interleukin-10 (IL-10) in response to LPS $[33,34]$. They also express high levels of MCP-1 receptor (CCR2) and L-Selectin (CD26L), alongside low levels of $\mathrm{CX} 3 \mathrm{C}-1$ chemokine receptor (CX3CR1), allowing quick recruitment to inflammatory signal-generating sites [34, 36]. This cellular subset has been identified as the main monocyte subtype involved in the inflammatory process at the atheromatous plaque, fundamentally due to their increased expression of CCR2 [37]. Furthermore, CCR2 in these cells may be a potential therapeutic target for modulation of their recruitment. In this regard, silencing of CCR2 in Ly-6C ${ }^{\text {hi }}$ monocytes in murine models, which are equivalent to $\mathrm{CD} 14^{++} \mathrm{CD} 16^{-}$monocytes in humans, has been linked to attenuation of the inflammatory response associated with atherosclerosis and myocardial infarction [38].

On the other hand, intermediate monocytes $\left[\mathrm{CD} 14^{++} \mathrm{CD} 16^{+}\right]$represent $2-10 \%$ of total circulating monocytes, show minimal peroxidase activity, and secrete large quantities of Interleukin-1 $\beta$ (IL-1 $\beta$ ) and TNF- $\alpha$ in response to LPS; thus, their role is preeminently proinflammatory, intensely expressing CXCR-1 and moderate amounts of CCR2 [33, 34]. Intermediate monocytes also express high levels of C-C chemokine receptor type 5 (CCR5), whose main ligand is CCL5, an important chemotactic molecule for $\mathrm{T}$ cells, allowing this subpopulation of monocytes to 


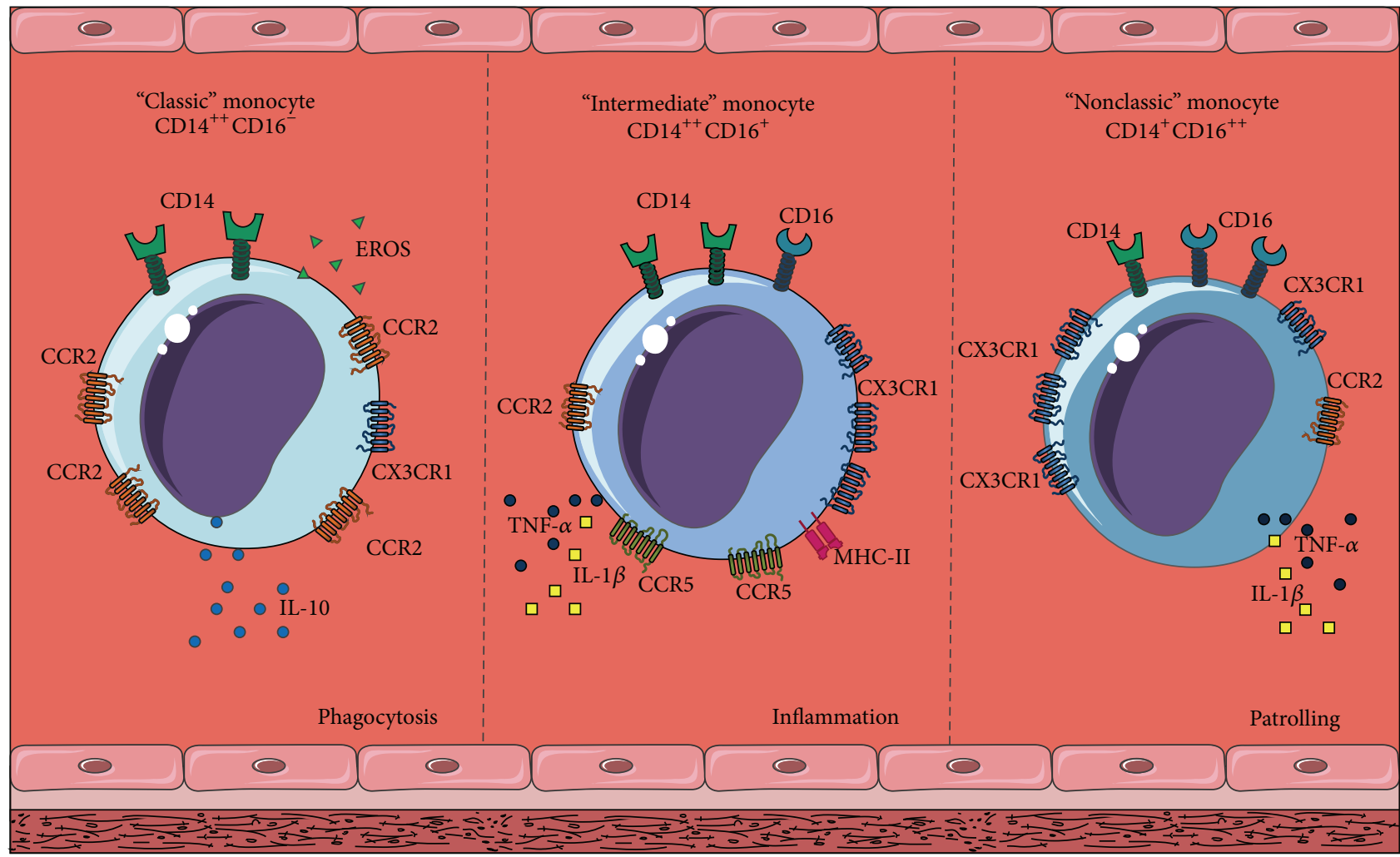

Figure 2: Monocyte heterogeneity. According to differential expression of specific cell surface markers and receptors, monocytes may be classified into three distinct subpopulations: "classic" monocytes $\left[\mathrm{CD} 14^{++} \mathrm{CD} 16^{-}\right]$, "intermediate" monocytes $\left[\mathrm{CD} 14^{++} \mathrm{CD} 16^{+}\right]$, and "nonclassic" monocytes $\left[\mathrm{CD} 14^{+} \mathrm{CD} 16^{++}\right]$.

participate in activation of $\mathrm{T}$ cells and amplification of local inflammatory activity $[33,34]$.

Finally, nonclassic monocytes $\left[\mathrm{CD} 14^{+} \mathrm{CD} 16^{++}\right]$comprise only $2-8 \%$ of total circulating monocytes and are considered "patrolling" or "surveillance" cells because they express low levels of CCR2 and high levels of CX3CR1, resulting in great endothelial affinity with a stunted response to chemotaxis [32, 39].

\section{Macrophage Heterogeneity}

Macrophages play a crucial role in immune responses, by actively participating in a myriad of biological processes, such as resolution of infections and repairing of injured tissues, as prompted by numerous signals, which include microbial molecules and proinflammatory cytokines [40]. Following differentiation from monocytes, macrophages may adopt various functional phenotypes as directed by diverse stimuli [41], a process that is species-specific and very finely regulated [42].

Macrophages adopt the M1 phenotype following binding of Interferon- $\gamma$ (IFN- $\gamma)$ to its extracellular heterodimeric receptors IFNGR-1 and IFNGR-2, which initiates JAK1- and JAK2-mediated signaling cascades, culminating in activation of STAT1, which in turn activates the transcriptome for the M1 profile [43]. These cells exhibit proinflammatory and phagocytic traits, expressing abundant membrane scavenger receptors which permit endocytosis of modified lipoproteins such as oxLDL [44].

The concept of macrophage "heterogeneity" was introduced after observations of monocytes undergoing macrophagic differentiation through an alternate route, towards a cellular subpopulation with different characteristics, termed M2 macrophages [40, 45]. Moreover, this alternative pathway may originate at least three well-defined macrophage subtypes: M2a, M2b, and M2c [46, 47], Figure 3. IL-4, released by Th2 lymphocytes, eosinophils, basophils, and macrophages, appears to be the principal messenger triggering the switch M2 [48]. After binding to its receptor (IL-4R), this cytokine starts JAK1- and JAK3-mediated intracellular cascade that finalizes in activation of STAT6, which then drives M2 differentiation [48]. IL-10 may also favor this switch through activation of JAK1-STAT3 [49], and glucocorticoids may directly promote transcription of M2 genes and silencing of M1-related genes, as part of their robust anti-inflammatory capabilities [50].

Each kind of M2 macrophage displays distinct biologic profiles. M2a are strongly anti-inflammatory, inhibiting release of INF- $\gamma$, IL-1, IL-6, IL-10, GM-CSF, and TNF- $\alpha$, have poor phagocytic capacity, and contribute to deposition of extracellular matrix by potentiating synthesis of polyamines, collagen, and Transforming Growth Factor- $\beta$ (TGF- $\beta$ ); thus, M2a may be described as "tissue-repairing" macrophages [51]. On the other hand, M2b and M2c, known as "regulator" 


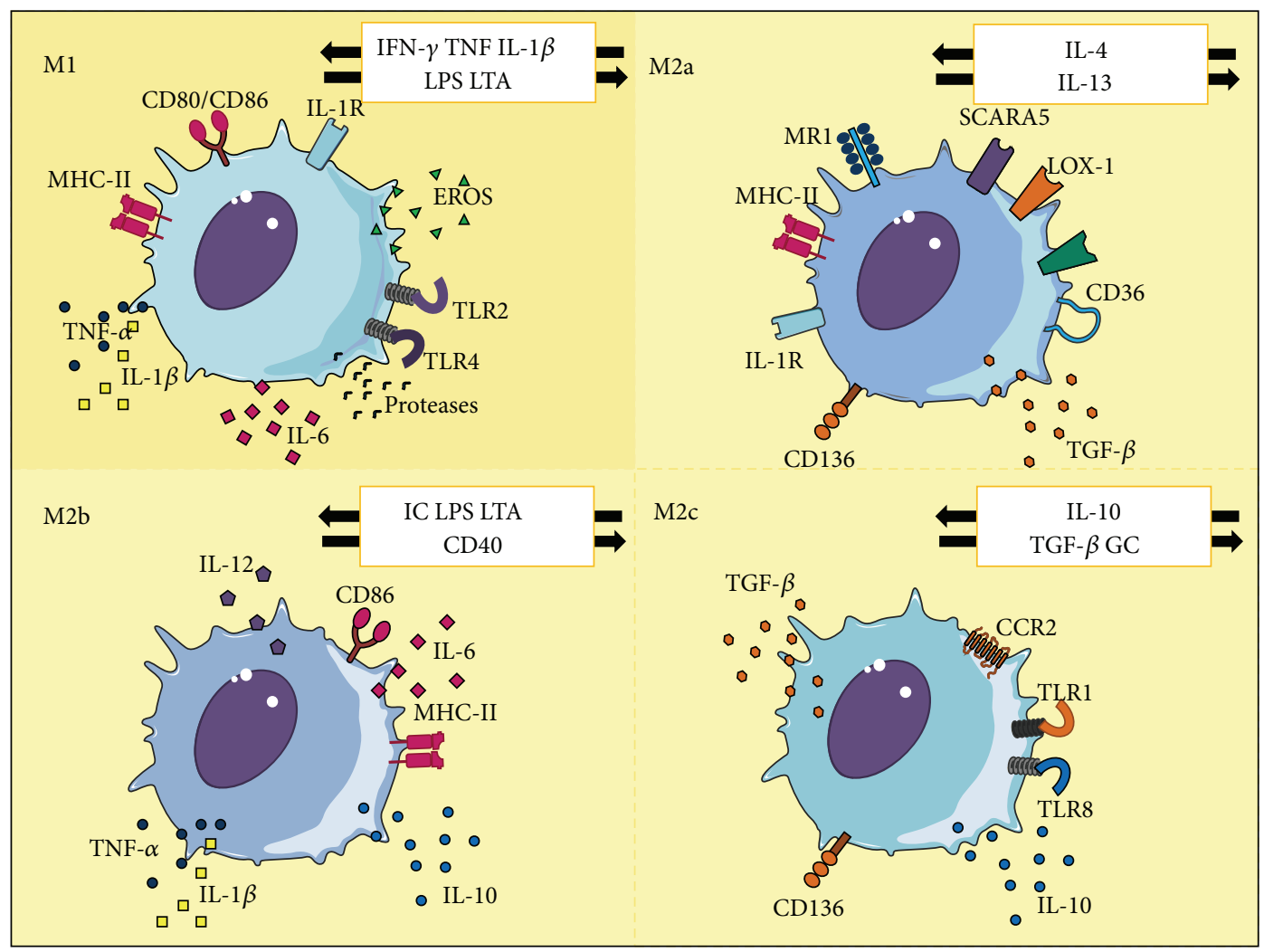

FIGURE 3: Macrophage heterogeneity. Monocyte activation and differentiation towards distinct macrophage subpopulations (M1 or M2) hinges on the predominant pro- or anti-inflammatory microenvironment within the lesion. M1 macrophages result from classic monocyte activation in response to proinflammatory stimuli, such as IFN- $\gamma$, TNF, IL- $1 \beta$, LPS, and LTA. On the other hand, M2 macrophages are subdivided into M2a, activated by IL-4 and IL-13; M2b, activated by IC, LPS, LTA, and CD40; and M2c, activated by IL-10, TGF- $\beta$, and GC. IFN- $\gamma$ : Interferon- $\gamma$, TNF: Tumoral Necrosis Factor, IL-1 $\beta$ : Interleukin-1 $\beta$, LPS: Lipopolysaccharide, LTA: lipoteichoic acid, IL-6: Interleukin6, IL-4: Interleukin-4, IL-13: Interleukin-13, TGF- $\beta$ : Transforming Growth Factor- $\beta$, IC: immune complexes, and GC: glucocorticoids.

macrophages, can limit tisular damage caused by prolonged activation of M1 macrophages by modulating numerous aspects of chronic inflammation [52]. However, they have been shown not to actively participate in tissue repairing, as they are unable to synthesize extracellular matrix, and express different chemokine receptors, in contrast with M2a macrophages [53].

On the other hand, transition to M2b may be triggered by exposure to immune complexes, TLR ligands, LPS, lipoteichoic acid, and other intermediaries. These cells boast remarkable IL-10 secretion associated with FoxO1 expression [54] and very low IL-12 release, along with moderate secretion of TNF- $\alpha$, IL-6, and IL-1 [55]. Lastly, M2c macrophages, whose activation may be driven by IL-10, TGF- $\beta$, or glucocorticoids, are also capable of abundant IL-10 release but are also able to inhibit production of proinflammatory cytokines, Nitric Oxide (NO), and Reactive Oxygen Species (ROS), outlining an important role in limiting progression of inflammation [56].

\section{From Endothelial Dysfunction to Atherosclerosis: A Quick Revision}

Atherosclerosis is a multifactorial, chronic, and progressive inflammatory process which develops from endothelial dysfunction [57]. The endothelium is a metabolically active organ, capable of producing a wide array of vasoactive messengers, notably NO, Prostacyclin $\mathrm{I}_{2}\left(\mathrm{PGI}_{2}\right)$, Endothelins (ET-1, ET-2, and ET-3), Thromboxane $\mathrm{A}_{2}$ (TXA $)$, and angiotensin II [58-60]. These mediators perform several functions, with some of them antagonistic in nature, in order to maintain vascular homeostasis in response to specific stimuli. The loss of this equilibrium, that is, endothelial dysfunction, sets the stage for the earliest phases of atherosclerosis [61]. This alteration is propitiated by various cardiovascular risk factors, such as dyslipidemia [62], uncontrolled Diabetes Mellitus (DM) [63], hypertension [64], and smoking [65]. These entities induce production of ROS, intensifying peroxynitrite-dependent oxidative stress and diminishing NO bioavailability by uncoupling the endothelial Nitric Oxide Synthase (eNOS) activity and transformation to peroxynitrite [66]. Other reactive species, including hydrogen peroxide, superoxide anions, and hypochlorous acid, also participate in this scenario, particularly by disrupting mitochondrial functionality [67].

The natural history of atherosclerotic disease may be studied in 6 continuous stages, from the formation of the lipid core to vascular lumen obliteration [68]. Elevated levels of low-density lipoprotein-cholesterol (LDL-C) appear to be 
essential mediators in Stage I, directly participating in the organization of the lipid core and promoting polarization of circulating monocytes towards proinflammatory phenotypes $\left(\mathrm{CD} 8^{+} \mathrm{CCR} 2^{+}\right)[69,70]$. LDL-C molecules are especially susceptible to oxidation within the plaque, owing to their subendothelial localization. This is facilitated by a vascular lumen/subendothelium gradient which allows passage of LDL-C to the latter, with anchorage to heparan-sulfate [71], and by marked structural instability of LDL-C due to high concentration of polyunsaturated fatty acids (PUFA) [71]. Nevertheless, native LDL-C is recognized by Class B scavenger receptors, which play a limited role in macrophage differentiation [72].

In Stage II [68], PUFA in LDL-C are rapidly peroxidized, producing lipid hydroperoxides which subsequently degenerate, yielding a complex mix of byproducts, including malondialdehyde, 4-hydroxynonenal, and hexanal $[73,74]$. These substances can interact with amino groups from Apoprotein B100 in LDL-C, modifying its structure via formation of Schiff bases (nonoxidative modification) between positively charged amino groups and aldehyde groups, producing modified LDL-C (mLDL-C). These molecules are highly antigenic and can be easily recognized by scavenger receptors for subsequent endocytosis and formation of foam cells [75].

Scavenger receptors are found in a broad array of cells, remarkably in macrophages, monocytes, platelets, endothelial cells, smooth muscle cells, and epithelial cells [76], mediating internalization of mLDL and other polyanionic ligands, such as oxLDL, acetylated LDL, Gram-positive and Gramnegative bacteria, apoptotic cells, and advanced glycation end products $[77,78]$. Activation of these receptors is a key immunologic event in the development of atherosclerosis, as it promotes chemotaxis in monocytes and neutrophils, differentiation of macrophages, and formation of foam cells [79]. These changes in macrophage functionality remain for extended periods of time due to epigenetic histone modifications [80].

In this stage, oxLDL are particularly potent mediators within the subendothelium, given their strong antigenicity and their ability to induce expression of genes involved in the inflammatory response in endothelial cells and macrophages. For instance, they are able to increase endothelial permeability via multiple mechanisms, such as cytoskeletal disorganization through inhibition of myosin light-chain phosphatase, with activation of Rho kinase [81], and promotion of heparanase secretion with heparan-sulfate degradation in the extracellular matrix, facilitating extravasation of immune cells to the intimal space of dysfunctional endothelium [82].

Nevertheless, one of the most notable roles of oxLDL is the induction of Nuclear Factor- $\kappa \mathrm{B}$ (NF- $\kappa \mathrm{B})$ [83-86], a key mediator in the perpetuation of the proinflammatory environment in the plaque [87], a crucial characteristic of Stage III [68]. Activation of NF- $\kappa$ B leads to expression of several cellular adhesion molecules like P-Selectin, Vascular Cell Adhesion Molecule-1 (VCAM-1), and Intercellular Adhesion Molecule-1 (ICAM-1), indispensable for the fixation of immune cells to the endothelium during chemotaxis $[88,89]$. Furthermore, Monocyte Chemoattractant Protein1 (MCP-1), a 76-amino acid peptide of the C-C chemokine family [90], is also induced in endothelial cells and vascular smooth muscle cells (VSMC) when stimulated by oxLDL, angiotensin II, C-Reactive Protein, and TNF- $\alpha$ [91]. MCP-1 is considered the principal chemotactic intermediary involved in regulation of migration and infiltration of monocytes, $\mathrm{T}$ cells, and NK cells to the subendothelium in the earlier stages of atherogenesis [72]. During Stage IV [68], chemokines induce VSMC proliferation and inhibit NO synthesis, actively contributing to the evolution and progression of atherosclerotic lesions [91]. Finally, Stages V and VI convey the formation of foam cells, derived not only from macrophages but also from VSMC and endothelial cells, calcification of the lipid core, organization of the fibrous cap, and development of plaque vulnerability, which ends in plaque rupture and exposure of the matrix, activation of platelets, and acute formation of thrombi [68].

Although formation of macrophage-derived foam cells requires activity from several scavenger receptors, CD36 from Class B appears to be the main mediator $[44,72,77$, $79,92]$. The CD36 intracellular signaling cascade involves phosphorylation of syn (an src/yes-related human gene) [93], fyn, and lyn ( $\operatorname{src}$ kinase) $[94,95]$, following activation of JNK1 and JNK2. This process culminates in oxLDL uptake via Vav, a guanine nucleotide exchange factor which acts as a scaffolding protein, modulating dynamin-dependent cytoskeletal processes [96]. Platelet-activating factor receptor [97] and Toll-like receptors (TLR) 4 and 6 [98] also appear to be required to be present in the same lipid raft as CD36 for oxLDL internalization. Activation of CD36 also triggers activation of inflammasomes and release of IL-1 $\beta$, loss of cell polarity, stunting of cell movement, inhibition of autophagy, and, finally, cell death [99]. Other factors appear to intervene in formation of macrophage-derived foam cells, including Bone-Morphogenetic Protein (BMP) 4 via Smad1/5/8 signaling [100], thymic stromal lymphopoietin [101], Visfatin [102], and TRAIL (Tumor Necrosis Factor-related apoptosisinducing ligand) [103] through induction of CD36 and/or scavenger receptor Class A (SR-A).

Development of foam cells derived from VSMC is another paramount aspect of advanced atherosclerotic lesions, due to their involvement in intimal thickening and stability of the fibrous cap $[68,104]$. Several VSMC phenotypes have been described, each with distinct responses to lipoproteins in in vitro models $[105,106]$. Immune cues, such as activation of TLR4, can induce formation of foam cells from VSMC via activation of NF- $\kappa$ B and induction of Acyl-coenzyme A:cholesterol acyltransferase 1 (ACAT1) [107]. Furthermore, molecules such as ezetimibe and TRPV1 have been shown to impede formation of VSMC-derived foam cells by preventing cholesterol accumulation [108] and promoting autophagy [109], respectively, highlighting the importance of these processes in this context. Recent research has also shown these cells carry cholesterol loads larger than previously considered, possibly linked to their relatively lower capacity for cholesterol release via ABCA1 and their ability to transdifferentiate towards a macrophage-like phenotype in advanced atherosclerosis [110, 111]. Finally, endothelium-derived foam cells display unique characteristics, such as expression of 
VCAM-1, increased intracellular calcium movement, and high levels of heat shock proteins [112].

\section{Macrophage Plasticity and Atherosclerosis: Echoing Dr. Jekyll and Mr. Hyde}

In addition to the processes and macrophage subtypes described previously, macrophages may shift between these phenotypes in response to certain signals within their dynamic local microenvironment [113], a property known as "plasticity." This mechanism allows adaptation to a myriad of possible changes in dysfunctional endothelium or damaged tissue, including acute oscillations in levels of lipids, ROS, proinflammatory cytokines, microbial products, or oxLDL [114]. Indeed, within the atheromatous plaque, microenvironmental cues define the predominating local macrophage phenotype [115]: M1 cells tend to accumulate in ruptureprone areas of the plaque, in contrast with M2 cells, which are principally found in stable regions of the atherosclerotic plaque, along with high IL-4 and IL-13 levels, away from the lipid nucleus [116], and are considered highly resistant to degeneration into foam cells [117]. Neither phenotype is particularly predominant in the fibrous layer of the atherosclerotic lesion [118].

As commented beforehand, the main command for M1 switching is IFN- $\gamma$ signaling $[43,44]$, with participation of other intermediaries, including Interferon regulatory factors (IRF). In this respect, IRF5 has been demonstrated to propel polarization towards the M1 phenotype and induce release of IL-12 and IL-23, propelling a powerful T helper Th1Th17 response [119]. Likewise, Notch signaling has been linked to increased M1 gene expression via IRF8 [120]. Interestingly, several microorganisms have been observed to trigger various intracellular pathways associated with M1 polarization, such as Listeria monocytogenes, Chlamydia ssp., and Salmonella typhimurium [121]. In fact, C. pneumoniae [122, 123], Helicobacter pylori [124], and Cytomegalovirus [125] have been identified in the atherosclerotic lesions, where they may promote polarization of the local macrophages towards the M1 phenotype and upregulate M1-related genes like TNF$\alpha$, IL-6, IL-1 $\beta$, CCL2, CCL5, and CXCL8 [126].

Obesity and various obesity-associated disorders, such as DM and metabolic syndrome, have been linked with imbalanced M1/M2 ratios [127], propitiated by the chronic, subclinical, and proinflammatory state promoted by adiposopathy and insulin resistance [128] and chronic insulitis [129]. Moreover, increased levels of $\mathrm{CD}^{+} 8^{+} \mathrm{M} 1$ macrophages have also been observed in premorbid states, such as prediabetes, where these cells have been reported to share a direct correlation with HbAlC levels [130]. One of the most important markers for subclinical inflammation is C-Reactive Protein (CRP) [131], a pentameric acute-phase protein. Concerning macrophage modulation, CRP has been associated with M1 polarization mediated by stimulation of $\mathrm{M}-\mathrm{CSF}$ secretion from endothelial cells and activation of NF$\kappa \mathrm{B}[132,133]$. Finally, low adiponectin levels, as seen in the presence of visceral obesity, also favor M1 polarization, as this hormone is a promoter of M2 switching through AMPK,
PPAR- $\gamma$, and PPAR- $\alpha$ [134]. Therefore, AMPK-activating drugs, such as metformin, may be useful in prevention of atherosclerosis $[25,26]$.

Other disorders featuring proinflammatory states, such as systemic lupus erythematosus (SLE) [135], rheumatoid arthritis (RA) [136], psoriasis [137], and antiphospholipid syndrome (APS) [138], have been associated with M1 polarization and higher risk for atherosclerosis and cardiovascular events. Reports on in vitro SLE models have described greater cholesterol accumulation in macrophages, along with increased IFN- $\alpha$ signaling and SR-A expression [135], as well as higher rates of macrophage-derived foam cell formation [139]. Likewise, subjects with SLE and RA exhibit higher levels of macrophage activation markers, such as neopterin [135] and macrophage migration inhibitory factor [140], as well as disorganized gene expression related to microbial translocation and immune dysregulation [141]. In APS, the TLR4 pathways appear particularly relevant as they intervene in the macrophage-foam cell transition induced by oxLDL/ $\beta 2$ GPI/anti- $\beta 2$ GPI complexes [138] and participate in what has been denominated "autoimmunemediated atherosclerosis," seen in these individuals [142, 143].

On the other hand, M2 polarization requires attenuation of various M1-promoting intermediaries. In this regard, the p50 subunit of NF- $\kappa \mathrm{B}$ has been observed to inhibit NF$\kappa \mathrm{B}$-induced M1 polarization [144]. Similarly, complement protein $\mathrm{Clq}$ has been found to suppress NF- $\kappa$ B activation in macrophages during lipoprotein endocytosis and processing, lowering release of inflammatory cytokines [145]. Other M2 promoters include Sphingosine-1-phosphate (S1P), an intermediary in the antiatherogenic functions of HDL-C, which increases IL- 4 secretion and upregulates IL- $4 \mathrm{R} \alpha$ and IL- $2 \mathrm{R} \gamma$ [146], and thioredoxin, which has been observed to potentiate IL-4-dependent M2-programming via downregulation of p16 ${ }^{\mathrm{INK} 4 \mathrm{a}}$, with accompanying reduction of lesion area in animal models [147].

As can be observed, macrophage polarization within a certain scenario is a game of power, whose outcome is dictated by the prevailing kind of microenvironmental stimuli [148-150]. The complex molecular interplay underlying M1/M2 switching represents intriguing enigma, with important implications for therapeutic intervention in CVD.

\section{Monocyte and Macrophage Migration}

One of the earliest events in the pathogenesis of the atherosclerotic plaque is the adhesion of circulating monocytes to the vascular endothelium, followed by their migration to the intima. Various adhesion molecules (P-Selectin, ICAM-1, and VCAM-1), chemoattractant cytokines, and modified lipoproteins are responsible for monocyte recruitment to the intima [151], whereas in vitro models have shown lysophosphatidic acid and platelet-activating factor to be the main factors involved in their retention within the subendothelium [152]. In this location, monocytes differentiate into macrophages, able to capture oxLDL through scavenger-type receptors, and finally become foam cells, a cornerstone of 
atheromatous lesions [153], highlighting the importance of monocyte retention for plaque progression [154].

In this regard, emigration of monocyte-derived cells from atherosclerotic lesions has been associated with their regression; thus, decreased efflux of these cells may be a key phenomenon for their progression [152, 155]. Netrin-1, a protein associated with tumorigenesis and axonal migration, may play a major role in this scenario, by interfering with macrophage traffic in atherosclerotic lesions and perpetuating the local inflammatory response [156].

Lastly, macrophage proliferation is yet another fundamental finding in atherosclerosis: this mechanism may originate up to $90 \%$ of all locally accumulated macrophages [157]. Although the relative importance of these three pathophysiologic components, monocyte recruitment, macrophage retention, and macrophage proliferation, in atherosclerosis remains a provocative topic of debate, the former two phenomena appear to be the most dominant during the earlier phases of the disease, whereas macrophage proliferation may be particularly salient in its advanced stages [158]. At any rate, current experimental evidence suggests monocyte recruitment may be the most viable target for therapeutic modulation of the atherosclerotic process [159].

\section{Macrophage Biomarkers: Role in the Inflammatory Response and Potential Clinical Applications}

Inflammation is a major component of CVD and a fundamental driving force throughout all phases of atherosclerosis [160], with macrophages being the principal cellular mediators, by secreting a wide array of molecules, such as cytokines, chemokines, growth factors, and proteases, all of which are involved in different stages of the disease [161]. In this context, these products may be considered biomarkers, complying with the NIH definition [162].

Results from recent prospective studies have shown control of atherosclerosis may be poor, despite optimal risk factor management [163], and progression rates to be similar irrespective of age [164]. Indeed, although the accumulation of cellular functional alterations attributable to chronic disease and senescence is intimately linked to inflammation [165], entailing pathogenic mechanisms such as mitochondrial dysfunction, oxidative stress, and immune-endocrine aging $[166,167]$, the increasing prevalence of obesity, smoking, hypertension, and other risk factors in younger populations may be shifting this paradigm $[17,168,169]$.

This alarming outlook accentuates the importance of assessing the potential benefits of targeting macrophage biomarkers for therapy, by either hindering proinflammatory pathways or enhancing anti-inflammatory mechanisms, while accounting for age and the impact of early intervention. Although many biomarkers have been associated with macrophage activation, their relationship with the different phenotypes remains unclear. Therefore, macrophage heterogeneity may represent a foundation for the study of their products' potential clinical applications, with respect to prediction of atherosclerotic progression and therapeutic modulation of the inflammatory response. This conundrum has already spawned a large body of research [170-172], Table 1. Nonetheless, to date, most of this research has been realized in animal models or in vitro, and many aspects remain incompletely elucidated in humans.

Interventions exploiting anti-inflammatory cytokines, such as IL-10, appear promising [173]. IL-10 has several antiatherogenic properties, regulating multiple immune functions and attenuating inflammation, chiefly through repression of IFN- $\gamma$ [174]. Indeed, IL-10-deficient mice exposed to an atherogenic diet have been found to exhibit prominent IFN- $\gamma$ expression, as well as greater-sized atherosclerotic lesions with significantly higher lipid deposition, lower collagen content, and increased $\mathrm{T}$ cell infiltration in comparison to mice with unaltered immune responses in equal conditions [175]. Similarly, Pinderski et al. [15] evidenced a significant decline in atherosclerotic progression in mice with $\mathrm{T}$ cells overexpressing IL-10, reflected in reduction of lesions, particularly in necrotic nuclei, and a pronounced decrease in lipidic accumulation in medium- and large-caliber arteries. Remarkably high IL-10 levels in specific areas within atherosclerotic lesions may obey a marked decrease in local expression of inducible Nitric Oxide Synthase (iNOS), along with macrophages with low apoptotic activity [176].

IL-13 has also demonstrated possibly exploitable antiatherogenic assets, as described by Cardilo-Reis et al. [16], who found IL-13 administration promoted favorable modifications in plaque morphology in $\mathrm{LDL}$ receptordeficient mice, with increased collagen synthesis and decreased VCAM-1-dependent monocyte recruitment. Furthermore, a decline in macrophage concentration was observed in lesions, along with M2 polarization. In addition, mice with IL-13 deficiency developed larger-sized, more advanced plaques and appeared to synthesize lower levels of IL-4 and IL-10, disfavoring alternative activation of macrophages. Finally, IL-19 and IL-27 also boast notorious antiatherogenic properties: treatment with IL-19 has been associated with Th2 polarization of lymphocytes and decreased macrophage infiltration in atherosclerotic lesions in murine models [177]. Similarly, in animal models, administration of IL-27 has been described to diminish LDL-C traffic in macrophages, limiting generation of foam cells [18], and increase synthesis of ABCA1 via JAK2/STAT3 [178], restricting progression of atherosclerotic lesions.

Modulation of PPAR- $\gamma$ in macrophages represents another alternative, due to their ability to inhibit expression of many inflammatory mediators [179]. Additionally, statin-mediated activation of PPAR- $\gamma$ in macrophages has been linked with improved insulin sensitivity and M2 polarization, with reduced inflammation and atherosclerotic progression, expanding these agents' well-established therapeutic role in the management of CVD beyond the management of dyslipidemia $[19,180]$. Indeed, statins boast a battery of pleiotropic effects, involved in anti-inflammatory, antioxidant, and immunomodulating mechanisms [181]. Youssef et al. [182] have proved statins to be able to shift the global immune environment towards anti-inflammation in murine models, with promotion of IL- 4 , IL-10, and TGF- $\beta$ 


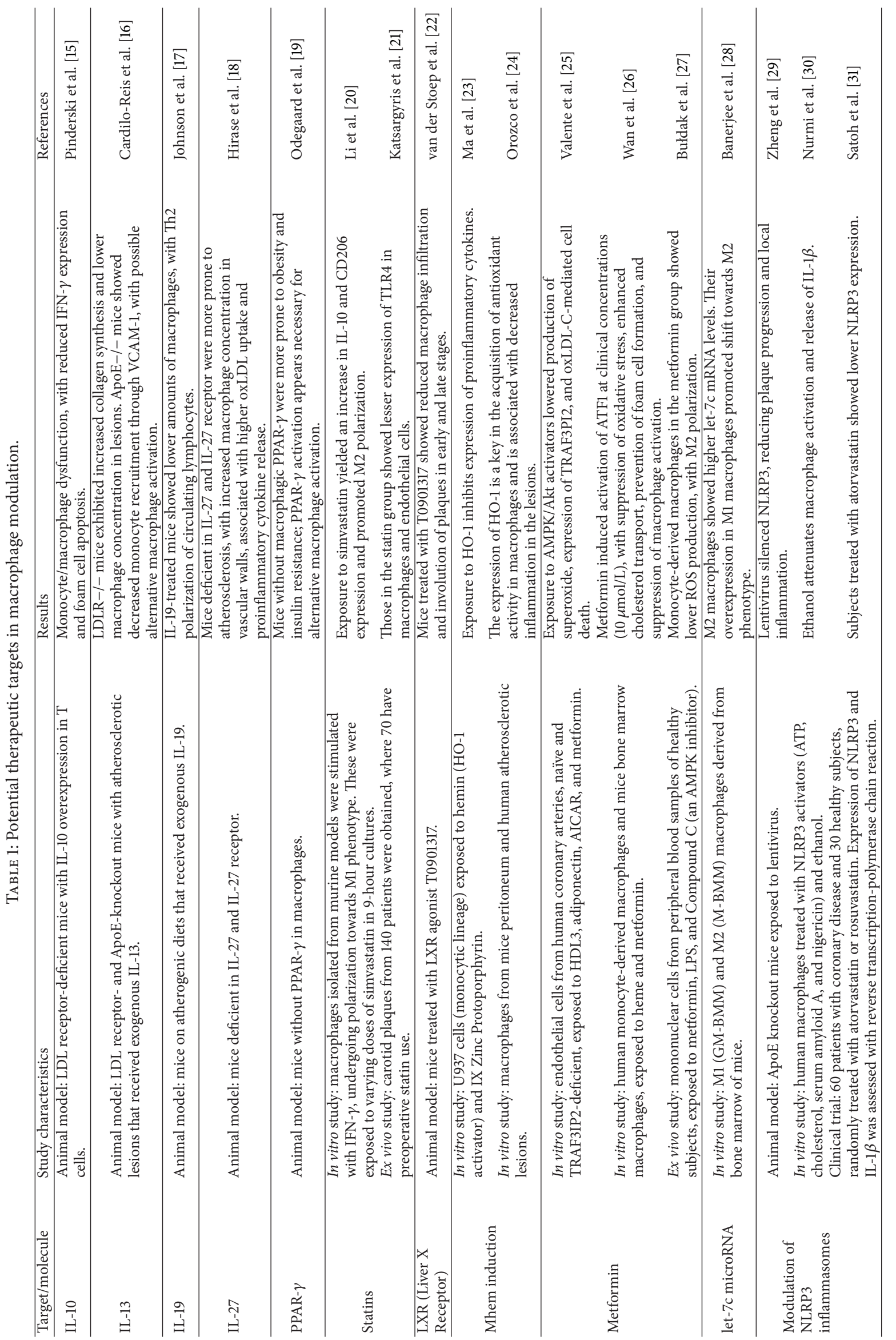


release and inhibition of proinflammatory messengers such as IL-12, TNF- $\alpha$, and IFN- $\gamma$, powerfully inducing M2 polarization in murine models [20].

In light of these molecular findings, statins have been suggested for use in primary prevention, supported by research with animal [183-186] and human models [187, 188]. However, there remains a scarcity of evidence in certain specific groups of patients [189]; and reports associating these drugs with dysglycemia have also raised concerns regarding their possible widespread utilization in a primary preventive scenario [190, 191]. This relationship should be reassessed in studies using statin doses capable of influencing formation or stabilization of atherosclerotic plaques and levels of biomarkers such as CRP and TLR4 [21, 192-194].

Therefore, currently available evidence is insufficient to recommend statin therapy as a primary preventive strategy $[195,196]$. Concerning secondary prevention, statins have been proven to be beneficial in patients with DM [197], hypertension [198], ST segment elevation myocardial infarction [199], and stroke [200]; and these effects may be present with both low-moderate and intensive statin therapy [201, 202]. Nevertheless, important side effects such as statin-associated myopathy [203-205] should be taken into account for long term pharmacological preventive interventions.

In any manner, statins may impact not only macrophages and endothelial cells, but also VSMC: pitavastatin and fluvastatin have been shown to lower expression of MCP-1 and TNF- $\alpha$ in these cells [206]. Likewise, atorvastatin has been observed to suppress TGF- $\beta 1$-induced calcification of VSCM and promote autophagy via blunting of $\beta$-catenin signaling [207]. Similarly, other kinds of agents, such as telmisartan (an angiotensin II receptor antagonist), have been demonstrated to induce autophagy in VSMC via activation of PPAR- $\gamma$ and AMPK and inhibition of mTOR [208].

Liver X Receptors (LXR) are important nuclear transcription factors in macrophages, with specific genomic targets, such as the LBP (Lipopolysaccharide Binding Protein) gene, involved in foam cell modulation via LXRa expression [22, $209,210]$, and control of iron depots and iron-dependent oxidative stress [208]. Iron management profiles are especially important in macrophages, as they allow categorization of macrophages into pro- and antiatherogenic subtypes [211-214], Figure 4. Proatherogenic macrophage phenotypes include (a) M1 and (b) Mox, which exhibit preference for lipid oxidation and are Nfr2-modulated and located in active plaques [215]. Antiatherogenic phenotypes include (a) M2 and (b) M4, which are CXCL4-induced and express low CD163 levels [216], (c) M(Hb), which are activated by hemoglobin-haptoglobin complexes [217], and (d) Mhem, heme-inducible macrophages, which are characteristically located in intraplaque hemorrhage sites, with high heme oxidase levels induced by Activating Transcription Factor-1 (ATF-1) $[23,24,213]$.

Other drugs, such as metformin, have also been described to intervene in macrophage functionality: this molecule can induce expression of AMPK and ATF-1, increasing heme concentration and thus driving Mhem polarization, ultimately preventing formation of foam cells [25]. Metformin has also been reported to lower ROS production and oxLDL-dependent cell death in human endothelial cells [26]. These pleotropic properties are considered to amplify this agent's effects on multiple cardiometabolic variables, such as lower mLDL-C levels [218] and enhanced activity of antioxidant enzymes like superoxide dismutase [219], and significantly attenuate the impact of atherogenic diets in vascular physiology [27].

In addition, microRNA (mRNA) molecules, short RNA sequences capable of regulating genetic expression, have recently claimed considerable interest as therapeutic targets in all genome-related diseases [220, 221], including atherosclerosis. These molecules may be exploited for the modulation of multiple inflammatory signaling cascades and macrophage polarization pathways [222]. Banerjee et al. [28] reported let-7c mRNA to suppress expression of M1 components in favor of a M2 phenotype, in consonance with similar descriptions by Zhuang et al. [223] in response to mRNA-233. Nevertheless, the study and application of mRNAs remain a vastly unknown yet encouraging field in regard to atherosclerosis and CVD.

Finally, regulation of NLRP3 inflammasome activation in M1 macrophages represents another novel alternative. In animal models, NLRP3 activation by ATP [224] and cholesterol crystals [225] is associated with increased lipid deposition and generation of foam cells, propelling its use as a marker for innate immune system activation in patients with coronary disease [226]. NLRP3 inhibition through silencing [29], or modulation with atorvastatin [31], ethanol [30], and scropolioside B [227], is associated with diminished oxLDL transport, NF- $\kappa \mathrm{B}$ inhibition, and deceleration of foam cell generation and plaque progression.

\section{Concluding Remarks}

The study of monocyte and macrophage heterogeneity has led to the identification of these cells' distinct functional phenotypes, which play dynamic roles in the onset and progression of atherosclerosis, as these cells may act as proor anti-inflammatory mediators, depending on the prevailing cues involved in their activation. A broad range of pre- and postpolarization biomarkers appear throughout this process, posing as valuable subjects for further investigation, in view of their possible applications in CVD.

As research efforts have advanced concerning macrophage activation and their associated biomarkers, new therapeutic targets have emerged in every stage of the atherosclerotic process. These innovative examples include modulation of macrophage autophagy [228-230], induction of IL-10 synthesis with conjugated linolenic acid [231], induction of M2 polarization through STAT3 via GLP-1 [232], inhibition of macrophage Notch1 [233], blocking of scavenger receptors such as CD68F [234], GABA- or topiramate-mediated inactivation of NF- $\kappa \mathrm{B}$ and $\mathrm{MAPK}^{\mathrm{p} 38}$ [235], and modulation of Treg cells in order to induce antiatherogenic macrophages [236]. Indeed, the future appears extraordinarily promising in this field, and further research is required in order to more thoroughly comprehend the molecular foundation of atherosclerosis and 


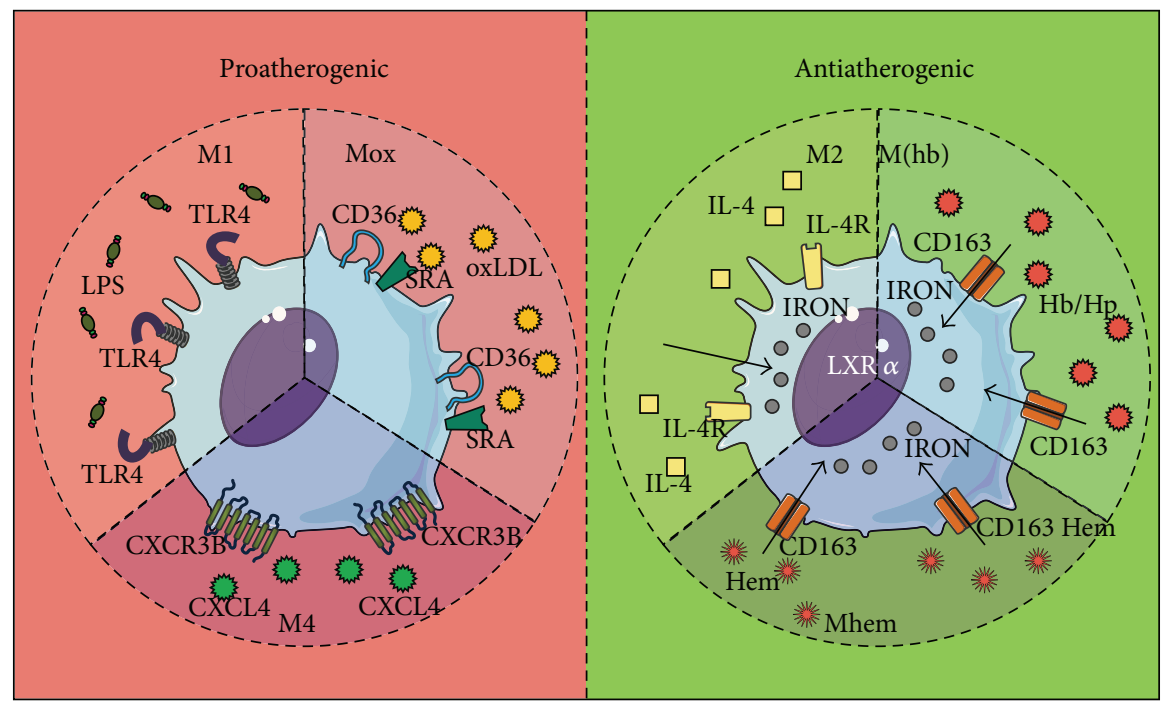

FIgURE 4: Proatherogenic and Antiatherogenic macrophages. Proatherogenic macrophages include M1 and Mox, whereas antiatherogenic macrophages include $\mathrm{M} 2, \mathrm{M} 4, \mathrm{M}(\mathrm{Hb})$, and Mhem. Each of these phenotypes varies in regard to associated stimuli and iron management.

to identify possible interventional targets and their impact in the clinical setting.

\section{Conflict of Interests}

There are no financial or other contractual agreements that might cause conflict of interests.

\section{References}

[1] World Health Organization, Global Status Report on Noncommunicable Diseases 2010, World Health Organization, Geneva, Switzerland, 2011, http://www.who.int/mediacentre/ factsheets/fs317/es/.

[2] C. D. Mathers and D. Loncar, "Projections of global mortality and burden of disease from 2002 to 2030," PLoS Medicine, vol. 3, no. 11, article e442, 2006.

[3] Ministerio del Poder Popular para la Salud, Anuario de Mortalidad 2010, Ministerio del Poder Popular para la Salud, Caracas, Venezuela, 2010, http://www.mpps.gob.ve/index.php? option $=$ com_phocadownload\&view=category\&id=11:anuarios-de-mortalidad.

[4] World Health Organization, Global Atlas on Cardiovascular Disease Prevention and Control, World Health Organization, Geneva, Switzerland, 2011, http://www.who.int/cardiovascular _diseases/publications/atlas_cvd/en/.

[5] P. Libby, P. M. Ridker, and G. K. Hansson, "Progress and challenges in translating the biology of atherosclerosis," Nature, vol. 473, no. 7347, pp. 317-325, 2011.

[6] H. A. R. Hadi, C. S. Carr, and J. S. Al Suwaidi, "Endothelial dysfunction: cardiovascular risk factors, therapy, and outcome," Vascular Health and Risk Management, vol. 1, no. 3, pp. 183-198, 2005.

[7] J. Mestas and K. Ley, "Monocyte-endothelial cell interactions in the development of atherosclerosis," Trends in Cardiovascular Medicine, vol. 18, no. 6, pp. 228-232, 2008.

[8] T. Gui, A. Shimokado, Y. Sun, T. Akasaka, and Y. Muragaki, "Diverse roles of macrophages in atherosclerosis: from inflammatory biology to biomarker discovery," Mediators of Inflammation, vol. 2012, Article ID 693083, 14 pages, 2012.

[9] D. Hashimoto, J. Miller, and M. Merad, "Dendritic cell and macrophage heterogeneity in vivo," Immunity, vol. 35, no. 3, pp. 323-335, 2011.

[10] S. Lee, S. Huen, H. Nishio et al., "Distinct macrophage phenotypes contribute to kidney injury and repair," Journal of the American Society of Nephrology, vol. 22, no. 2, pp. 317-326, 2011.

[11] M. A. Bouhlel, B. Derudas, E. Rigamonti et al., "PPAR $\gamma$ activation primes human monocytes into alternative M2 macrophages with anti-inflammatory properties," Cell Metabolism, vol. 6, no. 2, pp. 137-143, 2007.

[12] L. Chávez-Sánchez, J. E. Espinosa-Luna, K. Chávez-Rueda, M. V. Legorreta-Haquet, E. Montoya-Díaz, and F. Blanco-Favela, "Innate immune system cells in atherosclerosis," Archives of Medical Research, vol. 45, no. 1, pp. 1-14, 2014.

[13] I. Junttila, R. P. Bourette, L. R. Rohrschneider, and O. Silvennoinen, "M-CSF induced differentiation of myeloid precursor cells involves activation of PKC-delta and expression of Pkare," Journal of Leukocyte Biology, vol. 73, no. 2, pp. 281-288, 2003.

[14] A. Lehtonen, S. Matikainen, M. Miettinen, and I. Julkunen, "Granulocyte-macrophage colony-stimulating factor (GMCSF)-induced STAT5 activation and target-gene expression during human monocyte/macrophage differentiation," Journal of Leukocyte Biology, vol. 71, no. 3, pp. 511-519, 2002.

[15] L. J. Pinderski, M. P. Fischbein, G. Subbanagounder et al., "Overexpression of interleukin-10 by activated T lymphocytes inhibits atherosclerosis in LDL receptor-deficient mice by altering lymphocyte and macrophage phenotypes," Circulation Research, vol. 90, no. 10, pp. 1064-1071, 2002.

[16] L. Cardilo-Reis, S. Gruber, S. M. Schreier et al., "Interleukin-13 protects from atherosclerosis and modulates plaque composition by skewing the macrophage phenotype," EMBO Molecular Medicine, vol. 4, no. 10, pp. 1072-1086, 2012.

[17] H. M. Johnson, C. T. Thorpe, C. M. Bartels et al., "Undiagnosed hypertension among young adults with regular primary care use," Journal of Hypertension, vol. 32, no. 1, pp. 65-74, 2014. 
[18] T. Hirase, H. Hara, Y. Miyazaki et al., "Interleukin 27 inhibits atherosclerosis via immunoregulation of macrophages in mice," American Journal of Physiology - Heart and Circulatory Physiology, vol. 305, no. 3, pp. H420-H429, 2013.

[19] J. I. Odegaard, R. R. Ricardo-Gonzalez, M. H. Goforth et al., "Macrophage-specific PPAR $\gamma$ controls alternative activation and improves insulin resistance," Nature, vol. 447, no. 7148, pp. 1116-1120, 2007.

[20] Q.-Z. Li, J. Sun, J.-J. Han, and Z.-J. Qian, "Anti-inflammation of simvastatin by polarization of murine macrophages from M1 phenotype to M2 phenotype," Zhonghua Yi Xue Za Zhi, vol. 93, no. 26, pp. 2071-2074, 2013.

[21] A. Katsargyris, C. Klonaris, S. Tsiodras, E. Bastounis, A. Giannopoulos, and S. Theocharis, "Statin treatment is associated with reduced toll-like receptor 4 immunohistochemical expression on carotid atherosclerotic plaques: a novel effect of statins," Vascular, vol. 19, no. 6, pp. 320-326, 2011.

[22] M. van der Stoep, Z. Li, L. Calpe-Berdiel et al., "Elimination of macrophages drives LXR-induced regression both in initial and advanced stages of atherosclerotic lesion development," Biochemical Pharmacology, vol. 86, no. 11, pp. 1594-1602, 2013.

[23] J.-L. Ma, P.-Y. Yang, Y.-C. Rui, L. Lu, H. Kang, and J. Zhang, "Hemin modulates cytokine expressions in macrophagederived foam cells via heme oxygenase-1 induction," Journal of Pharmacological Sciences, vol. 103, no. 3, pp. 261-266, 2007.

[24] L. D. Orozco, M. H. Kapturczak, B. Barajas et al., "Heme oxygenase-1 expression in macrophages plays a beneficial role in atherosclerosis," Circulation Research, vol. 100, no. 12, pp. 17031711, 2007.

[25] A. J. Valente, A. M. Irimpen, U. Siebenlist, and B. Chandrasekar, "OxLDL induces endothelial dysfunction and death via TRAF3IP2: inhibition by HDL3 and AMPK activators," Free Radical Biology and Medicine, vol. 70, pp. 117-128, 2014.

[26] X. Wan, Y. Huo, M. Johns et al., “5'-AMP-activated protein kinase-activating transcription factor 1 cascade modulates human monocyte-derived macrophages to atheroprotective functions in response to heme or metformin," Arteriosclerosis, Thrombosis, and Vascular Biology, vol. 33, no. 11, pp. 2470-2480, 2013.

[27] Ł. Bułdak, K. Łabuzek, R. J. Bułdak et al., "Metformin affects macrophages' phenotype and improves the activity of glutathione peroxidase, superoxide dismutase, catalase and decreases malondialdehyde concentration in a partially AMPKindependent manner in LPS-stimulated human monoacytes/ macrophages," Pharmacological Reports, vol. 66, no. 3, pp. 418429, 2014.

[28] S. Banerjee, N. Xie, H. Cui et al., "microRNA let-7c regulates macrophage polarization," The Journal of Immunology, vol. 190, no. 12, pp. 6542-6549, 2013.

[29] F. Zheng, S. Xing, Z. Gong, W. Mu, and Q. Xing, "Silence of NLRP3 suppresses atherosclerosis and stabilizes plaques in apolipoprotein E-deficient mice," Mediators of Inflammation, vol. 2014, Article ID 507208, 8 pages, 2014.

[30] K. Nurmi, J. Virkanen, K. Rajamäki, K. Niemi, P. T. Kovanen, and K. K. Eklund, "Ethanol inhibits activation of NLRP3 and AIM2 inflammasomes in human macrophages-a novel antiinflammatory action of alcohol," PLoS ONE, vol. 8, no. 11, Article ID e78537, 2013.

[31] M. Satoh, T. Tabuchi, T. Itoh, and M. Nakamura, "NLRP3 inflammasome activation in coronary artery disease: results from prospective and randomized study of treatment with atorvastatin or rosuvastatin," Clinical Science, vol. 126, no. 3, pp. 233-241, 2014.

[32] D. Strauss-Ayali, S. M. Conrad, and D. M. Mosser, "Monocyte subpopulations and their differentiation patterns during infection," Journal of Leukocyte Biology, vol. 82, no. 2, pp. 244-252, 2007.

[33] L. Ziegler-Heitbrock, P. Ancuta, S. Crowe et al., "Nomenclature of monocytes and dendritic cells in blood," Blood, vol. 116, no. 16, pp. e74-e80, 2010.

[34] J. Yang, L. Zhang, C. Yu, X. Yang, and H. Wang, "Monocyte and macrophage differentiation: circulation inflammatory monocyte as biomarker for inflammatory diseases," Biomarker Research, vol. 2, article 1, 2014.

[35] K. L. Wong, J. J.-Y. Tai, W.-C. Wong et al., "Gene expression profiling reveals the defining features of the classical, intermediate, and nonclassical human monocyte subsets," Blood, vol. 118, no. 5, pp. e16-e31, 2011.

[36] S. Mosig, K. Rennert, S. Krause et al., "Different functions of monocyte subsets in familial hypercholesterolemia: potential function of $\mathrm{CD}_{14}{ }^{+} \mathrm{CD} 16^{+}$monocytes in detoxification of oxidized LDL," The FASEB Journal, vol. 23, no. 3, pp. 866-874, 2009.

[37] A. Parihar, T. D. Eubank, and A. I. Doseff, "Monocytes and macrophages regulate immunity through dynamic networks of survival and cell death," Journal of Innate Immunity, vol. 2, no. 3, pp. 204-215, 2010.

[38] F. Leuschner, P. Dutta, R. Gorbatov et al., "Therapeutic siRNA silencing in inflammatory monocytes in mice," Nature Biotechnology, vol. 29, no. 11, pp. 1005-1010, 2011.

[39] J. Cros, N. Cagnard, K. Woollard et al., "Human CD14dim monocytes patrol and sense nucleic acids and viruses via TLR7 and TLR8 receptors," Immunity, vol. 33, no. 3, pp. 375-386, 2010.

[40] S. Colin, M. Fanchon, L. Belloy et al., "HDL does not influence the polarization of human monocytes toward an alternative phenotype," International Journal of Cardiology, vol. 172, no. 1, pp. 179-184, 2014.

[41] K. Ley, Y. I. Miller, and C. C. Hedrick, "Monocyte and macrophage dynamics during atherogenesis," Arteriosclerosis, Thrombosis, and Vascular Biology, vol. 31, no. 7, pp. 1506-1516, 2011.

[42] F. Gantner, R. Kupferschmidt, C. Schudt, A. Wendel, and A. Hatzelmann, "In vitro differentiation of human monocytes to macrophages: change of PDE profile and its relationship to suppression of tumour necrosis factor- $\alpha$ release by PDE inhibitors," British Journal of Pharmacology, vol. 121, no. 2, pp. 221-231, 1997.

[43] S. J. Waddell, S. J. Popper, K. H. Rubins et al., "Dissecting interferon-induced transcriptional programs in human peripheral blood cells," PLoS ONE, vol. 5, no. 3, Article ID e9753, 2010.

[44] V. V. Kunjathoor, M. Febbraio, E. A. Podrez et al., "Scavenger receptors class A-I/II and CD36 are the principal receptors responsible for the uptake of modified low density lipoprotein leading to lipid loading in macrophages," The Journal of Biological Chemistry, vol. 277, no. 51, pp. 49982-49988, 2002.

[45] J. J. Anzinger, J. Chang, Q. Xu et al., "Native low-density lipoprotein uptake by macrophage colony-stimulating factordifferentiated human macrophages is mediated by macropinocytosis and micropinocytosis," Arteriosclerosis, Thrombosis, and Vascular Biology, vol. 30, no. 10, pp. 2022-2031, 2010.

[46] A. Varin and S. Gordon, "Alternative activation of macrophages: immune function and cellular biology," Immunobiology, vol. 214, no. 7, pp. 630-641, 2009. 
[47] D. M. Mosser and J. P. Edwards, "Exploring the full spectrum of macrophage activation," Nature Reviews Immunology, vol. 8, no. 12, pp. 958-969, 2008.

[48] F. O. Martinez, L. Helming, R. Milde et al., "Genetic programs expressed in resting and IL-4 alternatively activated mouse and human macrophages: similarities and differences," Blood, vol. 121, no. 9, pp. e57-e69, 2013.

[49] D. F. Fiorentino, M. W. Bond, and T. R. Mosmann, “Two types of mouse Thelper cell. IV. Th2 clones secrete a factor that inhibits cytokine production by Th1 clones," The Journal of Experimental Medicine, vol. 170, no. 6, pp. 2081-20095, 1989.

[50] J. Ehrchen, L. Steinmüller, K. Barczyk et al., "Glucocorticoids induce differentiation of a specifically activated, antiinflammatory subtype of human monocytes," Blood, vol. 109, no. 3, pp. 1265-1274, 2007.

[51] T. J. Koh and L. A. DiPietro, "Inflammation and wound healing: the role of the macrophage," Expert Reviews in Molecular Medicine, vol. 13, article e23, 2011.

[52] G. Chinetti-Gbaguidi and B. Staels, "Macrophage polarization in metabolic disorders: functions and regulation," Current Opinion in Lipidology, vol. 22, no. 5, pp. 365-372, 2011.

[53] B. D. Fleming and D. M. Mosser, "Regulatory macrophages: setting the threshold for therapy," European Journal of Immunology, vol. 41, no. 9, pp. 2498-2502, 2011.

[54] S. Chung, R. Ranjan, Y. G. Lee et al., "Distinct role of FoxO1 in M-CSF- and GM-CSF-differentiated macrophages contributes LPS-mediated IL-10: implication in hyperglycemia," Journal of Leukocyte Biology, vol. 97, no. 2, pp. 327-339, 2015.

[55] F. O. Martinez, A. Sica, A. Mantovani, and M. Locati, "Macrophage activation and polarization," Frontiers in Bioscience, vol. 13, no. 2, pp. 453-461, 2008.

[56] M. A. Duque Correa and M. Rojas López, "Alternative macrophage activation: the diversity of one cell involved in innate immunity in response to its environmental complexity," Inmunologia, vol. 26, no. 2, pp. 73-86, 2007.

[57] D. H. Endemann and E. L. Schiffrin, "Endothelial dysfunction," Journal of the American Society of Nephrology, vol. 15, no. 8, pp. 1983-1992, 2004.

[58] H. F. Galley and N. R. Webster, "Physiology of the endothelium," British Journal of Anaesthesia, vol. 93, no. 1, pp. 105-113, 2004.

[59] U. Förstermann and T. Münzel, "Endothelial nitric oxide synthase in vascular disease: from marvel to menace," Circulation, vol. 113, no. 13, pp. 1708-1714, 2006.

[60] C. M. Kolka and R. N. Bergman, "The barrier within: endothelial transport of hormones," Physiology, vol. 27, no. 4, pp. 237247, 2012.

[61] M. E. Widlansky, N. Gokce, J. F. Keaney Jr., and J. A. Vita, “The clinical implications of endothelial dysfunction," Journal of the American College of Cardiology, vol. 42, no. 7, pp. 1149-1160, 2003.

[62] T. J. Anderson and F. Charbonneau, "Dyslipidemia and endothelial dysfunction: pathophysiology and therapy," in Endothelial Dysfunctions in Vascular Disease, R. De Caterina and P. Libby, Eds., chapter 17, Blackwell Publishing, Oxford, UK, 2007.

[63] A. Avogaro, M. Albiero, L. Menegazzo, S. de Kreutzenberg, and G. P. Fadini, "Endothelial dysfunction in diabetes: the role of reparatory mechanisms," Diabetes Care, vol. 34, supplement 2, pp. S285-S290, 2011.

[64] G. S. Sainani and V. G. Maru, "Role of endothelial cell dysfunction in essential hypertension," Journal of Association of Physicians of India, vol. 52, pp. 966-969, 2004.
[65] H. M. Johnson, L. K. Gossett, M. E. Piper et al., "Effects of smoking and smoking cessation on endothelial function: 1year outcomes from a randomized clinical trial," Journal of the American College of Cardiology, vol. 55, no. 18, pp. 1988-1995, 2010.

[66] N. M. Hamburg and J. A. Vita, "Endothelial dysfunction in atherosclerosis: mechanisms of impaired nitric oxide bioactivity," in Molecular Mechanisms of Atherosclerosis, J. Loscalzo, Ed., pp. 95-110, Taylor \& Francis, London, UK, 2005.

[67] J. K. Freed and D. D. Gutterman, "Mitochondrial reactive oxygen species and vascular function: less is more," Arteriosclerosis, Thrombosis, and Vascular Biology, vol. 33, no. 4, pp. 673-675, 2013.

[68] M. Simionescu and A. V. Sima, "Morphology of atherosclerotic lesions," in Inflammation and Atherosclerosis, G. Wick and C. Grundtman, Eds., pp. 19-37, Springer, Vienna, Austria, 2012.

[69] P. Nigro, J.-I. Abe, and B. C. Berk, "Flow shear stress and atherosclerosis: a matter of site specificity," Antioxidants and Redox Signaling, vol. 15, no. 5, pp. 1405-1414, 2011.

[70] G. P. Fadini, F. Simoni, R. Cappellari et al., "Pro-inflammatory monocyte-macrophage polarization imbalance in human hypercholesterolemia and atherosclerosis," Atherosclerosis, vol. 237, no. 2, pp. 805-808, 2014.

[71] Y. Pérez, "Oxidación de las LDL (lipoproteínas de baja densidad) y su relación con la patogénesis de la aterosclerosis," Revista CENIC Ciencias Biológicas, vol. 38, no. 1, pp. 3-11, 2007.

[72] F. J. Sheedy, A. Grebe, K. J. Rayner et al., "CD36 coordinates NLRP3 inflammasome activation by facilitating intracellular nucleation of soluble ligands into particulate ligands in sterile inflammation," Nature Immunology, vol. 14, no. 8, pp. 812-820, 2013.

[73] G. Ceballos Reyes, I. Ramírez, C. Calzada-Mendoza, and I. Olivares-Corichi, "Disfunción endotelial y estrés oxidativo," Revista de Endocrinología y Nutrición, vol. 14, no. 4, pp. 233236, 2006.

[74] M. Repetto, J. Semprine, and A. Boveris, "Lipid peroxidation: chemical mechanism, biological implications and analytical determination," in Lipid Peroxidation, A. Catala, Ed., InTech, Rijeka, Croatia, 2012.

[75] H. H. F. Refsgaard, L. Tsai, and E. R. Stadtman, "Modifications of proteins by polyunsaturated fatty acid peroxidation products," Proceedings of the National Academy of Sciences of the United States of America, vol. 97, no. 2, pp. 611-616, 2000.

[76] S. L. Stephen, K. Freestone, S. Dunn et al., "Scavenger receptors and their potential as therapeutic targets in the treatment of cardiovascular disease," International Journal of Hypertension, vol. 2010, Article ID 646929, 21 pages, 2010.

[77] D. R. Greaves and S. Gordon, "The macrophage scavenger receptor at 30 years of age: current knowledge and future challenges," Journal of Lipid Research, vol. 50, supplement, pp. S282-S286, 2009.

[78] J. Canton, D. Neculai, and S. Grinstein, "Scavenger receptors in homeostasis and immunity," Nature Reviews Immunology, vol. 13, no. 9, pp. 621-634, 2013.

[79] K. J. Moore and M. W. Freeman, "Scavenger receptors in atherosclerosis: beyond lipid uptake," Arteriosclerosis, Thrombosis, and Vascular Biology, vol. 26, no. 8, pp. 1702-1711, 2006.

[80] S. Bekkering, J. Quintin, L. A. B. Joosten, J. W. M. van der Meer, M. G. Netea, and N. P. Riksen, "Oxidized low-density lipoprotein induces long-term proinflammatory cytokine production and foam cell formation via epigenetic reprogramming of 
monocytes," Arteriosclerosis, Thrombosis, and Vascular Biology, vol. 34, no. 8, pp. 1731-1738, 2014.

[81] F. J. Byfield, S. Tikku, G. H. Rothblat, K. J. Gooch, and I. Levitan, "OxLDL increases endothelial stiffness, force generation, and network formation," Journal of Lipid Research, vol. 47, no. 4, pp. 715-723, 2006.

[82] A. Pirillo, G. D. Norata, and A. L. Catapano, "LOX-1, OxLDL, and atherosclerosis," Mediators of Inflammation, vol. 2013, Article ID 152786, 12 pages, 2013.

[83] T. B. Rajavashisth, H. Yamada, and N. K. Mishra, "Transcriptional activation of the macrophage-colony stimulating factor gene by minimally modified LDL. Involvement of nuclear factor- $\kappa \mathrm{B}$," Arteriosclerosis, Thrombosis, and Vascular Biology, vol. 15, no. 10, pp. 1591-1598, 1995.

[84] T. A. Hamilton, J. A. Major, D. Armstrong, and J. M. Tebo, "Oxidized LDL modulates activation of NFאB in mononuclear phagocytes by altering the degradation of I $\kappa$ Bs," Journal of Leukocyte Biology, vol. 64, no. 5, pp. 667-674, 1998.

[85] C. Mazière and J.-C. Mazière, "Activation of transcription factors and gene expression by oxidized low density lipoprotein," Free Radical Biology and Medicine, vol. 46, no. 2, pp. 127-137, 2009.

[86] C.-S. Huang, A.-H. Lin, C.-T. Liu et al., "Isothiocyanates protect against oxidized LDL-induced endothelial dysfunction by upregulating Nrf2-dependent antioxidation and suppressing NFKB activation," Molecular Nutrition and Food Research, vol. 57, no. 11, pp. 1918-1930, 2013.

[87] S. Xanthoulea, D. M. J. Curfs, M. H. Hofker, and M. P. J. De Winther, "Nuclear factor kappaB signaling in macrophage function and atherogenesis," Current Opinion in Lipidology, vol. 16, no. 5, pp. 536-542, 2005.

[88] Y. Ahn, Y. S. Kim, and M. H. Jeong, "The role of nuclear factor kappa B activation in atherosclerosis and ischemic cardiac injury," Korean Circulation Journal, vol. 36, no. 4, pp. 245-251, 2006.

[89] K. Van der Heiden, S. Cuhlmann, L. A. Luong, M. Zakkar, and P. C. Evans, "Role of nuclear factor $\kappa \mathrm{B}$ in cardiovascular health and disease," Clinical Science, vol. 118, no. 10, pp. 593-605, 2010.

[90] J. R. Harrington, “The role of MCP-1 in atherosclerosis," Stem Cells, vol. 18, no. 1, pp. 65-66, 2000.

[91] L. C. Becker, "Yin and Yang of MCP-1," Circulation Research, vol. 96, no. 8, pp. 812-814, 2005.

[92] W. Liu, Y. Yin, Z. Zhou, M. He, and Y. Dai, "OxLDL-induced IL-1beta secretion promoting foam cells formation was mainly via CD36 mediated ROS production leading to NLRP3 inflammasome activation," Inflammation Research, vol. 63, no. 1, pp. 33-43, 2014.

[93] K. Semba, M. Nishizawa, N. Miyajima et al., "Yes-related protooncogene, syn, belongs to the protein-tyrosine kinase family," Proceedings of the National Academy of Sciences of the United States of America, vol. 83, no. 15, pp. 5459-5463, 1986.

[94] M.-M. Huang, J. B. Bolen, J. W. Barnwell, S. J. Shattil, and J. S. Brugge, "Membrane glycoprotein IV (CD36) is physically associated with the Fyn, Lyn, and Yes protein-tyrosine kinases in human platelets," Proceedings of the National Academy of Sciences of the United States of America, vol. 88, no. 17, pp. 7844$7848,1991$.

[95] K. Chen, M. Febbraio, W. Li, and R. L. Silverstein, "A specific CD36-dependent signaling pathway is required for platelet activation by oxidized low-density lipoprotein," Circulation Research, vol. 102, no. 12, pp. 1512-1519, 2008.
[96] S. O. Rahaman, G. Zhou, and R. L. Silverstein, "Vav protein guanine nucleotide exchange factor regulates CD36 proteinmediated macrophage foam cell formation via calcium and dynamin-dependent processes," The Journal of Biological Chemistry, vol. 286, no. 41, pp. 36011-36019, 2011.

[97] F. J. O. Rios, M. Ferracini, M. Pecenin et al., "Uptake of oxLDL and IL-10 production by macrophages requires PAFR and CD36 recruitment into the same lipid rafts," PLoS ONE, vol. 8, no. 10, Article ID e76893, 2013.

[98] C. R. Stewart, L. M. Stuart, K. Wilkinson et al., "CD36 ligands promote sterile inflammation through assembly of a Toll-like receptor 4 and 6 heterodimer," Nature Immunology, vol. 11, no. 2, pp. 155-161, 2010.

[99] Y. M. Park, "CD36, a scavenger receptor implicated in atherosclerosis," Experimental and Molecular Medicine, vol. 46, no. 6, article e99, 2014.

[100] J. Feng, J. Gao, Y. Li et al., "BMP4 enhances foam cell formation by BMPR-2/SMAD1/5/8 signaling," International Journal of Molecular Sciences, vol. 15, no. 4, pp. 5536-5552, 2014.

[101] D.-Z. Li, B.-Y. Wang, B.-J. Yang et al., "Thymic stromal lmphopoietin pomotes macrophage-derived foam cell formation," Journal of Huazhong University of Science and Technology: Medical Science, vol. 34, no. 1, pp. 23-28, 2014.

[102] F. Zhou, Y. Pan, Z. Huang et al., "Visfatin induces cholesterol accumulation in macrophages through up-regulation of scavenger receptor-A and CD36," Cell Stress and Chaperones, vol. 18, no. 5, pp. 643-652, 2013.

[103] F. F. Liu, X. Wu, Y. Zhang, Y. Wang, and F. Jiang, “TRAIL/DR5 signaling promotes macrophage foam cell formation by modulating scavenger receptor expression," PLoS ONE, vol. 9, no. 1, Article ID e87059, 2014.

[104] J. L. Johnson, "Emerging regulators of vascular smooth muscle cell function in the development and progression of atherosclerosis," Cardiovascular Research, vol. 103, no. 4, pp. 452-460, 2014.

[105] S. Li, Y.-S. Fan, L. H. Chow et al., "Innate diversity of adult human arterial smooth muscle cells: cloning of distinct subtypes from the internal thoracic artery," Circulation Research, vol. 89, no. 6, pp. 517-525, 2001.

[106] C. A. Argmann, C. G. Sawyez, S. Li et al., "Human smooth muscle cell subpopulations differentially accumulate cholesteryl ester when exposed to native and oxidized lipoproteins," Arteriosclerosis, Thrombosis, and Vascular Biology, vol. 24, no. 7, pp. 1290-1296, 2004.

[107] Y. W. Yin, S. Q. Liao, M. J. Zhang et al., "TLR4-mediated inflammation promotes foam cell formation of vascular smooth muscle cell by upregulating ACAT1 expression," Cell Death \& Disease, vol. 5, no. 12, Article ID e1574, 2014.

[108] L. Qin, Y.-B. Yang, Y.-X. Yang et al., "Ezetimibe suppresses cholesterol accumulation in lipid-loaded vascular smooth muscle cells in vitro via MAPK signaling," Acta Pharmacologica Sinica, vol. 35, no. 9, pp. 1129-1136, 2014.

[109] B.-H. Li, Y.-W. Yin, Y. Liu et al., "TRPV1 activation impedes foam cell formation by inducing autophagy in oxLDL-treated vascular smooth muscle cells," Cell Death and Disease, vol. 5, no. 4, Article ID el182, 2014.

[110] S. Allahverdian, A. C. Chehroudi, B. M. McManus, T. Abraham, and G. A. Francis, "Contribution of intimal smooth muscle cells to cholesterol accumulation and macrophage-like cells in human atherosclerosis," Circulation, vol. 129, no. 15, pp. 15511559, 2014. 
[111] D. Gomez and G. K. Owens, "Smooth muscle cell phenotypic switching in atherosclerosis," Cardiovascular Research, vol. 95, no. 2, pp. 156-164, 2012.

[112] L. Ivan and F. Antohe, "Hyperlipidemia induces endothelialderived foam cells in culture," Journal of Receptors and Signal Transduction, vol. 30, no. 2, pp. 106-114, 2010.

[113] A. Sica and A. Mantovani, "Macrophage plasticity and polarization: in vivo veritas," Journal of Clinical Investigation, vol. 122, no. 3, pp. 787-795, 2012.

[114] A. Mantovani, S. K. Biswas, M. R. Galdiero, A. Sica, and M. Locati, "Macrophage plasticity and polarization in tissue repair and remodelling," Journal of Pathology, vol. 229, no. 2, pp. 176185, 2013.

[115] B. D. MacNeill, I.-K. Jang, B. E. Bouma et al., "Focal and multifocal plaque macrophage distributions in patients with acute and stable presentations of coronary artery disease," Journal of the American College of Cardiology, vol. 44, no. 5, pp. 972-979, 2004.

[116] N. Leitinger and I. G. Schulman, "Phenotypic polarization of macrophages in atherosclerosis," Arteriosclerosis, Thrombosis, and Vascular Biology, vol. 33, no. 6, pp. 1120-1126, 2013.

[117] G. Chinetti-Gbaguidi, M. Baron, M. A. Bouhlel et al., "Human atherosclerotic plaque alternative macrophages display low cholesterol handling but high phagocytosis because of distinct activities of the PPAR $\gamma$ and LXR $\alpha$ pathways," Circulation Research, vol. 108, no. 8, pp. 985-995, 2011.

[118] J. L. Stöger, M. J. J. Gijbels, S. van der Velden et al., "Distribution of macrophage polarization markers in human atherosclerosis," Atherosclerosis, vol. 225, no. 2, pp. 461-468, 2012.

[119] T. Krausgruber, K. Blazek, T. Smallie et al., "IRF5 promotes inflammatory macrophage polarization and TH1-TH17 responses," Nature Immunology, vol. 12, no. 3, pp. 231-238, 2011.

[120] H. Xu, J. Zhu, S. Smith et al., "Notch-RBP-J signaling regulates the transcription factor IRF8 to promote inflammatory macrophage polarization," Nature Immunology, vol. 13, no. 7, pp. 642-650, 2012.

[121] A. C. Labonte, A.-C. Tosello-Trampont, and Y. S. Hahn, "The role of macrophage polarization in infectious and inflammatory diseases," Molecules and Cells, vol. 37, no. 4, pp. 275-285, 2014.

[122] M. Izadi, M. Fazel, M. Akrami et al., "Chlamydia pneumoniae in the atherosclerotic plaques of coronary artery disease patients," Acta Medica Iranica, vol. 51, no. 12, pp. 864-870, 2013.

[123] Y. V. Bobryshev, A. N. Orekhov, M. C. Killingsworth, and J. $\mathrm{Lu}$, "Decreased expression of liver X receptor- $\alpha$ in macrophages infected with Chlamydia pneumoniae in human atherosclerotic arteries in situ," Journal of Innate Immunity, vol. 3, no. 5, pp. 483-494, 2011.

[124] M. Kowalski, "Helicobacter pylori (H. pylori) infection in coronary artery disease: influence of $H$. pylori eradication on coronary artery lumen after percutaneous transluminal coronary angioplasty. The detection of $H$. pylori specific dna in human coronary atherosclerotic plaque," Journal of Physiology and Pharmacology, vol. 52, no. 1, supplement 1, pp. 3-31, 2001.

[125] K. C. Yaiw, O. Ovchinnikova, C. Taher et al., "High prevalence of human cytomegalovirus in carotid atherosclerotic plaques obtained from Russian patients undergoing carotid endarterectomy," Herpesviridae, vol. 4, no. 1, article 3, 2013.

[126] M. Benoit, B. Desnues, and J.-L. Mege, "Macrophage polarization in bacterial infections," Journal of Immunology, vol. 181, no. 6, pp. 3733-3739, 2008.
[127] M. J. Kraakman, A. J. Murphy, K. Jandeleit-Dahm, and H. L. Kammoun, "Macrophage polarization in obesity and type 2 diabetes: weighing down our understanding of macrophage function?" Frontiers in Immunology, vol. 5, article 470, 2014.

[128] H. Kitade, K. Sawamoto, M. Nagashimada et al., "CCR5 plays a critical role in obesity-induced adipose tissue inflammation and insulin resistance by regulating both macrophage recruitment and M1/M2 status," Diabetes, vol. 61, no. 7, pp. 1680-1690, 2012.

[129] H. Cucak, L. G. Grunnet, and A. Rosendahl, "Accumulation of M1-like macrophages in type 2 diabetic islets is followed by a systemic shift in macrophage polarization," Journal of Leukocyte Biology, vol. 95, no. 1, pp. 149-160, 2014.

[130] G. P. Fadini, R. Cappellari, M. Mazzucato, C. Agostini, S. Vigili de Kreutzenberg, and A. Avogaro, "Monocyte-macrophage polarization balance in pre-diabetic individuals," Acta Diabetologica, vol. 50, no. 6, pp. 977-982, 2013.

[131] H. S. Park, J. Y. Park, and R. Yu, "Relationship of obesity and visceral adiposity with serum concentrations of CRP, TNF- $\alpha$ and IL-6," Diabetes Research and Clinical Practice, vol. 69, no. 1, pp. 29-35, 2005.

[132] S. Devaraj and I. Jialal, "C-reactive protein polarizes human macrophages to an $\mathrm{M} 1$ phenotype and inhibits transformation to the M2 phenotype," Arteriosclerosis, Thrombosis, and Vascular Biology, vol. 31, no. 6, pp. 1397-1402, 2011.

[133] S. Devaraj, J.-M. Yun, C. Duncan-Staley, and I. Jialal, "C-reactive protein induces M-CSF release and macrophage proliferation," Journal of Leukocyte Biology, vol. 85, no. 2, pp. 262-267, 2009.

[134] F. Lovren, Y. Pan, A. Quan et al., "Adiponectin primes human monocytes into alternative anti-inflammatory M2 macrophages," The American Journal of Physiology - Heart and Circulatory Physiology, vol. 299, no. 3, pp. H656-H663, 2010.

[135] J. Li, Q. Fu, H. Cui et al., "Interferon- $\alpha$ priming promotes lipid uptake and macrophage-derived foam cell formation: a novel link between interferon- $\alpha$ and atherosclerosis in lupus," Arthritis and Rheumatism, vol. 63, no. 2, pp. 492-502, 2011.

[136] Y. H. Rho, J. Solus, P. Raggi et al., "Macrophage activation and coronary atherosclerosis in systemic lupus erythematosus and rheumatoid arthritis," Arthritis Care \& Research, vol. 63, no. 4, pp. 535-541, 2011.

[137] F. Späh, "Inflammation in atherosclerosis and psoriasis: common pathogenic mechanisms and the potential for an integrated treatment approach," British Journal of Dermatology, vol. 159, no. 2, pp. 10-17, 2008.

[138] X. Zhang, Y. Xie, H. Zhou et al., "Involvement of TLR4 in oxidized LDL/ $\beta 2 \mathrm{GPI} /$ Anti- $\beta 2 \mathrm{GPI}$-induced transformation of macrophages to foam cells," Journal of Atherosclerosis and Thrombosis, vol. 21, no. 11, pp. 1140-1151, 2014.

[139] A. B. Reiss, K. Anwar, J. T. Merrill et al., "Plasma from systemic lupus patients compromises cholesterol homeostasis: a potential mechanism linking autoimmunity to atherosclerotic cardiovascular disease," Rheumatology International, vol. 30, no. 5, pp. 591-598, 2010.

[140] L. L. Santos and E. F. Morand, "Macrophage migration inhibitory factor: a key cytokine in RA, SLE and atherosclerosis," Clinica Chimica Acta, vol. 399, no. 1-2, pp. 1-7, 2009.

[141] L. Shi, Z. Zhang, A. M. Yu et al., “The SLE transcriptome exhibits evidence of chronic endotoxin exposure and has widespread dysregulation of non-coding and coding RNAs," PLOS ONE, vol. 9, no. 5, Article ID e93846, 2014.

[142] L. R. Lopez, K. Kobayashi, Y. Matsunami, and E. Matsuura, "Immunogenic oxidized low-density lipoprotein/beta2glycoprotein I complexes in the diagnostic management of 
atherosclerosis," Clinical Reviews in Allergy and Immunology, vol. 37, no. 1, pp. 12-19, 2009.

[143] L. R. Lopez, M. Salazar-Paramo, C. Palafox-Sanchez, B. L. Hurley, E. Matsuura, and I. G.-D. La Torre, "Oxidized low-density lipoprotein and $\beta 2$-glycoprotein I in patients with systemic lupus erythematosus and increased carotid intima-media thickness: implications in autoimmune-mediated atherosclerosis," Lupus, vol. 15, no. 2, pp. 80-86, 2006.

[144] C. Porta, M. Rimoldi, G. Raes et al., "Tolerance and M2 (alternative) macrophage polarization are related processes orchestrated by p50 nuclear factor $\kappa \mathrm{B}$," Proceedings of the National Academy of Sciences of the United States of America, vol. 106, no. 35, pp. 14978-14983, 2009.

[145] W. Spivia, P. S. Magno, P. Le, and D. A. Fraser, "Complement protein Clq promotes macrophage anti-inflammatory M2-like polarization during the clearance of atherogenic lipoproteins," Inflammation Research, vol. 63, no. 10, pp. 885-93, 2014.

[146] S.-J. Park, K.-P. Lee, S. Kang et al., "Sphingosine 1-phosphate induced anti-atherogenic and atheroprotective M2 macrophage polarization through IL-4," Cellular Signalling, vol. 26, no. 10, pp. 2249-2258, 2014.

[147] K. El Hadri, D. F. D. Mahmood, D. Couchie et al., "Thioredoxin1 promotes anti-inflammatory macrophages of the M2 phenotype and antagonizes atherosclerosis," Arteriosclerosis, Thrombosis, and Vascular Biology, vol. 32, no. 6, pp. 1445-1452, 2012.

[148] F. De Paoli, B. Staels, and G. Chinetti-Gbaguidi, "Macrophage phenotypes and their modulation in atherosclerosis," Circulation Journal, vol. 78, no. 8, pp. 1775-1781, 2014.

[149] J. Khallou-Laschet, A. Varthaman, G. Fornasa et al., "Macrophage plasticity in experimental atherosclerosis," PLoS ONE, vol. 5, no. 1, Article ID e8852, 2010.

[150] D. Zhou, C. Huang, Z. Lin et al., "Macrophage polarization and function with emphasis on the evolving roles of coordinated regulation of cellular signaling pathways," Cellular Signalling, vol. 26, no. 2, pp. 192-197, 2014.

[151] K. Ley, Y. I. Miller, and C. C. Hedrick, "Monocyte and macrophage dynamics during atherogenesis," Arteriosclerosis, Thrombosis, and Vascular Biology, vol. 31, no. 7, pp. 1506-1516, 2011.

[152] J. Llodrá, V. Angeli, J. Liu, E. Trogan, E. A. Fisher, and G. J. Rendolph, "Emigration of monocyte-derived cells from atherosclerotic lesions characterizes regressive, but not progressive, plaques," Proceedings of the National Academy of Sciences of the United States of America, vol. 101, no. 32, pp. 11779-11784, 2004.

[153] A. C. Li and C. K. Glass, "The macrophage foam cell as a target for therapeutic intervention," Nature Medicine, vol. 8, no. 11, pp. 1235-1242, 2002.

[154] B. Ludewig and J. D. Laman, "The in and out of monocytes in atherosclerotic plaques: balancing inflammation through migration," Proceedings of the National Academy of Sciences of the United States of America, vol. 101, no. 32, pp. 11529-11530, 2004.

[155] R. R. S. Packard and G.-P. Shi, "Atherosclerosis progression and monocyte emigration from plaque," Future Cardiology, vol. 2, no. 4, pp. 415-418, 2006.

[156] J. M. van Gils, M. C. Derby, L. R. Fernandes et al., "The neuroimmune guidance cue netrin-1 promotes atherosclerosis by inhibiting the emigration of macrophages from plaques," Nature Immunology, vol. 13, no. 2, pp. 136-143, 2012.

[157] C. S. Robbins, I. Hilgendorf, G. F. Weber et al., "Local proliferation dominates lesional macrophage accumulation in atherosclerosis," Nature Medicine, vol. 19, no. 9, pp. 1166-1172, 2013.

[158] I. Hilgendorf, F. K. Swirski, and C. S. Robbins, "Monocyte fate in atherosclerosis," Arteriosclerosis, Thrombosis, and Vascular Biology, vol. 35, no. 2, pp. 272-279, 2014.

[159] S. Potteaux, E. L. Gautier, S. B. Hutchison et al., "Suppressed monocyte recruitment drives macrophage removal from atherosclerotic plaques of Apoe-/- mice during disease regression," The Journal of Clinical Investigation, vol. 121, no. 5, pp. 2025-2036, 2011.

[160] P. Libby, "Inflammation in atherosclerosis," Nature, vol. 420, no. 6917, pp. 868-874, 2002.

[161] S. Kofler, T. Nickel, and M. Weis, "Role of cytokines in cardiovascular diseases: a focus on endothelial responses to inflammation," Clinical Science, vol. 108, no. 3, pp. 205-213, 2005.

[162] Biomarkers Definitions Working Group, "Biomarkers and surrogate endpoints: preferred definitions and conceptual framework," Clinical Pharmacology \& Therapeutics, vol. 69, no. 3, pp. 89-95, 2001.

[163] A. W. Schoenenberger, P. Jamshidi, R. Kobza et al., "Progression of coronary artery disease during long-term follow-up of the Swiss Interventional Study on Silent Ischemia Type II (SWISSI II)," Clinical Cardiology, vol. 33, no. 5, pp. 289-295, 2010.

[164] L. Hernando-Marrupe, A. Suarez-Cuervo, R. HernándezAntolin et al., "Implications of age in coronary artery disease progression. A serial, volumetric, intravascular ultrasound study," European Heart Journal, vol. 34, supplement 1, Article ID P2416, 2013.

[165] N. S. Jenny, "Inflammation in aging: cause, effect, or both?" Discovery medicine, vol. 13, no. 73, pp. 451-460, 2012.

[166] R. S. Sohal and W. C. Orr, "The redox stress hypothesis of aging," Free Radical Biology and Medicine, vol. 52, no. 3, pp. 539-555, 2012.

[167] T. Singh and A. B. Newman, "Inflammatory markers in population studies of aging," Ageing Research Reviews, vol. 10, no. 3, pp. 319-329, 2011.

[168] S. A. Cunningham, M. R. Kramer, and K. M. Venkat Narayan, "Incidence of childhood obesity in the United States," The New England Journal of Medicine, vol. 370, no. 5, pp. 403-411, 2014.

[169] G. Jamil, M. Jamil, H. Alkhazraji et al., "Risk factor assessment of young patients with acute myocardial infarction," American Journal of Cardiovascular Disease, vol. 3, no. 3, pp. 170-174, 2013.

[170] W. F. Fearon and D. T. Fearon, "Inflammation and cardiovascular disease role of the interleukin-1 receptor antagonist," Circulation, vol. 117, no. 20, pp. 2577-2579, 2008.

[171] Z. Awan and J. Genest, "Inflammation modulation and cardiovascular disease prevention," European Journal of Preventive Cardiology, vol. 22, no. 6, pp. 719-733, 2015.

[172] F. De Paoli, B. Staels, and G. Chinetti-Gbaguidi, "Macrophage phenotypes and their modulation in atherosclerosis," Circulation Journal, vol. 78, no. 8, pp. 1775-1781, 2014.

[173] P. Welsh, H. M. Murray, I. Ford et al., "Circulating interleukin10 and risk of cardiovascular events: a prospective study in the elderly at risk," Arteriosclerosis, Thrombosis, and Vascular Biology, vol. 31, no. 10, pp. 2338-2344, 2011.

[174] R. P. Fernández and J. C. Kaski, "Interleukin-10 and coronary disease," Revista Española de Cardiología, vol. 55, no. 7, pp. 738750, 2002.

[175] Z. Mallat, S. Besnard, M. Duriez et al., "Protective role of interleukin-10 in atherosclerosis," Circulation Research, vol. 85, no. 8, pp. e17-e24, 1999. 
[176] Z. Mallat, C. Heymes, J. Ohan, E. Faggin, G. Lesèche, and A. Tedgui, "Expression of interleukin-10 in advanced human atherosclerotic plaques: relation to inducible nitric oxide synthase expression and cell death," Arteriosclerosis, Thrombosis, and Vascular Biology, vol. 19, no. 3, pp. 611-616, 1999.

[177] S. Ellison, K. Gabunia, S. E. Kelemen et al., "Attenuation of experimental atherosclerosis by interleukin-19," Arteriosclerosis, Thrombosis, and Vascular Biology, vol. 33, no. 10, pp. 2316-2324, 2013.

[178] H. Fu, Y.-Y. Tang, X.-P. Ouyang et al., "Interleukin-27 inhibits foam cell formation by promoting macrophage ABCA1 expression through JAK2/STAT3 pathway," Biochemical and Biophysical Research Communications, vol. 452, no. 4, pp. 881-887, 2014.

[179] M. A. Bouhlel, B. Derudas, E. Rigamonti et al., "PPARgamma activation primes human monocytes into alternative M2 macrophages with anti-inflammatory properties," Cell Metabolism, vol. 6, no. 2, pp. 137-143, 2007.

[180] F. Taylor, M. D. Huffman, A. F. Macedo et al., "Statins for the primary prevention of cardiovascular disease," Cochrane Database of Systematic Reviews, vol. 1, Article ID CD004816, 2013.

[181] B. Kwak, F. Mulhaupt, S. Myit, and F. Mach, "Statins as a newly recognized type of immunomodulator," Nature Medicine, vol. 6, no. 12, pp. 1399-1402, 2000.

[182] S. Youssef, O. Stüve, J. O. Patarroyo et al., "The HMGCoA reductase inhibitor, atorvastatin, promotes a Th2 bias and reverses paralysis in central nervous system autoimmune disease," Nature, vol. 420, no. 6911, pp. 78-84, 2002.

[183] E. D. Sezer, E. Y. Sozmen, D. Nart, and T. Onat, "Effect of atorvastatin therapy on oxidantantioxidant status and atherosclerotic plaque formation," Vascular Health and Risk Management, vol. 7, no. 1, pp. 333-343, 2011.

[184] M. Janić, M. Lunder, J. Zupan et al., “The low-dose atorvastatin and valsartan combination effectively protects the arterial wall from atherogenic diet-induced impairment in the guinea pig," European Journal of Pharmacology, vol. 743, pp. 31-36, 2014.

[185] M. Lunder, G. Drevenšek, D. Černe, J. Marc, M. Janić, and M. Šabovič, "Treatment with low-dose atorvastatin, losartan, and their combination increases expression of vasoactive-related genes in rat aortas," Journal of Cardiovascular Pharmacology and Therapeutics, vol. 18, no. 2, pp. 177-183, 2013.

[186] Y. Sun, J. Liu, B. Yang et al., "Inhibitory effect of coadministration of atorvastatin and endothelin-1 receptor antagonist on the progression of atherosclerosis in rabbit," APMIS, vol. 122, no. 6, pp. 556-564, 2014.

[187] P. M. Ridker, E. Danielson, F. A. H. Fonseca et al., "Rosuvastatin to prevent vascular events in men and women with elevated Creactive protein," The New England Journal of Medicine, vol. 359, no. 21, pp. 2195-2207, 2008.

[188] B. C. Fellström, A. G. Jardine, R. E. Schmieder et al., "Rosuvastatin and cardiovascular events in patients undergoing hemodialysis," The New England Journal of Medicine, vol. 360, no. 14, pp. 1395-1407, 2009.

[189] V. Narla, M. J. Blaha, R. S. Blumenthal, and E. D. Michos, “The JUPITER and AURORA clinical trials for rosuvastatin in special primary prevention populations: perspectives, outcomes, and consequences," Vascular Health and Risk Management, vol. 5, pp. 1033-1042, 2009.

[190] S. Erqou, C. C. Lee, and A. I. Adler, "Statins and glycaemic control in individuals with diabetes: a systematic review and meta-analysis," Diabetologia, vol. 57, no. 12, pp. 2444-2452, 2014.
[191] Y.-W. Wu, H.-L. Kao, C.-L. Huang et al., "The effects of 3month atorvastatin therapy on arterial inflammation, calcification, abdominal adipose tissue and circulating biomarkers," European Journal of Nuclear Medicine and Molecular Imaging, vol. 39, no. 3, pp. 399-407, 2012.

[192] E. McFadden, R. Stevens, P. Glasziou, and R. Perera, "Implications of lower risk thresholds for statin treatment in primary prevention: analysis of CPRD and simulation modelling of annual cholesterol monitoring," Preventive Medicine, vol. 70, pp. 14-16, 2015.

[193] B. Liu, J.-Y. Zhang, H.-M. Cao, Q. Wang, and H.-B. Wang, "Effect of rosuvastatin on ROCK activity, endothelial function, and inflammation in Asian patients with atherosclerosis," Internal Medicine, vol. 51, no. 10, pp. 1177-1182, 2012.

[194] A. O. Abdel-Zaher, A. E. A. Elkoussi, L. H. Abudahab, M. H. Elbakry, and E. A.-E. Elsayed, "Simvastatin enhances the antihypertensive effect of ramipril in hypertensive hypercholesterolemic animals and patients. Possible role of nitric oxide, oxidative stress, and high sensitivity C-reactive protein," Fundamental and Clinical Pharmacology, vol. 26, no. 6, pp. 701711, 2012.

[195] H. E. Bays, "Adiposopathy, diabetes mellitus, and primary prevention of atherosclerotic coronary artery disease: treating 'sick fat' through improving fat function with antidiabetes therapies," The American Journal of Cardiology, vol. 110, supplement, no. 9, pp. 4B-12B, 2012.

[196] W. S. Weintraub, S. R. Daniels, L. E. Burke et al., "Value of primordial and primary prevention for cardiovascular disease: a policy statement from the American Heart Association," Circulation, vol. 124, no. 8, pp. 967-990, 2011.

[197] V. G. Athyros, N. Katsiki, A. Karagiannis, and D. P. Mikhailidis, "High-intensity statin therapy and regression of coronary atherosclerosis in patients with diabetes mellitus," Journal of Diabetes and its Complications, vol. 29, no. 1, pp. 142-145, 2015.

[198] Z. Liu, Y. Zhao, F. Wei et al., "Treatment with telmisar$\tan /$ rosuvastatin combination has a beneficial synergistic effect on ameliorating Th17/Treg functional imbalance in hypertensive patients with carotid atherosclerosis," Atherosclerosis, vol. 233, no. 1, pp. 291-299, 2014.

[199] R. Egede, L. O. Jensen, H. S. Hansen et al., "Effect of intensive lipid-lowering treatment compared to moderate lipid-lowering treatment with rosuvastatin on endothelial function in high risk patients," International Journal of Cardiology, vol. 158, no. 3, pp. 376-379, 2012.

[200] M. Vrecer, S. Turk, J. Drinovec, and A. Mrhar, "Use of statins in primary and secondary prevention of coronary heart disease and ischemic stroke. Meta-analysis of randomized trials," International Journal of Clinical Pharmacology and Therapeutics, vol. 41, no. 12, pp. 567-577, 2003.

[201] S. Mora, N. K. Wenger, D. A. Demicco et al., "Determinants of residual risk in secondary prevention patients treated with high-versus low-dose statin therapy: the treating to new targets (TNT) study," Circulation, vol. 125, no. 16, pp. 1979-1987, 2012.

[202] T. R. Pedersen, O. Faergeman, J. J. P. Kastelein et al., "High-dose atorvastatin vs usual-dose simvastatin for secondary prevention after myocardial infarction: the IDEAL study: a randomized controlled trial," Journal of the American Medical Association, vol. 294, no. 19, pp. 2437-2445, 2005.

[203] K. Sakamoto and J. Kimura, "Mechanism of statin-induced rhabdomyolysis," Journal of Pharmacological Sciences, vol. 123, no. 4, pp. 289-294, 2013. 
[204] K. A. Antons, C. D. Williams, S. K. Baker, and P. S. Phillips, "Clinical perspectives of statin-induced rhabdomyolysis," The American Journal of Medicine, vol. 119, no. 5, pp. 400-409, 2006.

[205] M. Vrablik, L. Zlatohlavek, T. Stulc et al., "Statin-associated myopathy: from genetic predisposition to clinical management," Physiological Research, vol. 63, pp. S327-S334, 2014.

[206] K. Fukuda, T. Matsumura, T. Senokuchi et al., "Statins meditate anti-atherosclerotic action in smooth muscle cells by peroxisome proliferator-activated receptor- $\gamma$ activation," Biochemical and Biophysical Research Communications, vol. 457, no. 1, pp. 23-30, 2015.

[207] D. Liu, W. Cui, B. Liu et al., "Atorvastatin protects vascular smooth muscle cells from TGF- $\beta 1$-stimulated calcification by inducing autophagy via suppression of the $\beta$-catenin pathway," Cellular Physiology and Biochemistry, vol. 33, no. 1, pp. 129-141, 2014.

[208] B.-H. Li, S.-Q. Liao, Y.-W. Yin et al., “Telmisartan-induced $\operatorname{PPAR} \gamma$ activity attenuates lipid accumulation in VSMCs via induction of autophagy," Molecular Biology Reports, vol. 42, no. 1, pp. 179-186, 2014.

[209] M. Parikh, K. Patel, S. Soni, and T. Gandhi, "Liver X receptor: a cardinal target for atherosclerosis and beyond," Journal of Atherosclerosis and Thrombosis, vol. 21, no. 6, pp. 519-531, 2014.

[210] T. Sallam, A. Ito, X. Rong et al., "The macrophage LBP gene is an LXR target that promotes macrophage survival and atherosclerosis," Journal of Lipid Research, vol. 55, no. 6, pp. 1120-1130, 2014.

[211] G. Bories, S. Colin, J. Vanhoutte et al., "Liver X receptor activation stimulates iron export in human alternative macrophages," Circulation Research, vol. 113, no. 11, pp. 1196-1205, 2013.

[212] A. H. Hasty and L. Yvan-Charvet, "Liver X receptor $\alpha$ dependent iron handling in M2 macrophages: the missing link between cholesterol and intraplaque hemorrhage?" Circulation Research, vol. 113, no. 11, pp. 1182-1185, 2013.

[213] J. J. Boyle, M. Johns, T. Kampfer et al., "Activating transcription factor 1 directs Mhem atheroprotective macrophages through coordinated iron handling and foam cell protection," Circulation Research, vol. 110, no. 1, pp. 20-33, 2012.

[214] S. Colin, G. Chinetti-Gbaguidi, and B. Staels, "Macrophage phenotypes in atherosclerosis," Immunological Reviews, vol. 262, no. 1, pp. 153-166, 2014.

[215] A. Kadl, A. K. Meher, P. R. Sharma et al., "Identification of a novel macrophage phenotype that develops in response to atherogenic phospholipids via Nrf2," Circulation Research, vol. 107, no. 6, pp. 737-746, 2010.

[216] C. A. Gleissner, "Macrophage phenotype modulation by CXCL4 in atherosclerosis," Frontiers in Physiology, vol. 3, article 1, 2012.

[217] A. V. Finn, M. Nakano, R. Polavarapu et al., "Hemoglobin directs macrophage differentiation and prevents foam cell formation in human atherosclerotic plaques," Journal of the American College of Cardiology, vol. 59, no. 2, pp. 166-177, 2012.

[218] F. Forouzandeh, G. Salazar, N. Patrushev et al., "Metformin beyond diabetes: pleiotropic benefits of metformin in attenuation of atherosclerosis," Journal of the American Heart Association, vol. 3, no. 6, Article ID e001202, 2014.

[219] M. Ohira, T. Yamaguchi, A. Saiki et al., "Metformin reduces circulating malondialdehyde-modified low-density lipoprotein in type 2 diabetes mellitus," Clinical and Investigative Medicine, vol. 37, no. 4, pp. E243-E251, 2014.

[220] X. Liu, K. Fortin, and Z. Mourelatos, "MicroRNAs: biogenesis and molecular functions," Brain Pathology, vol. 18, no. 1, pp. 113121, 2008.
[221] R. W. Carthew and E. J. Sontheimer, "Origins and mechanisms of miRNAs and siRNAs," Cell, vol. 136, no. 4, pp. 642-655, 2009.

[222] G. Liu and E. Abraham, "MicroRNAs in immune response and macrophage polarization," Arteriosclerosis, Thrombosis, and Vascular Biology, vol. 33, no. 2, pp. 170-177, 2013.

[223] G. Zhuang, C. Meng, X. Guo et al., "A novel regulator of macrophage activation: MiR-223 in obesity-associated adipose tissue inflammation," Circulation, vol. 125, no. 23, pp. 28922903, 2012.

[224] X. Li, Y. Zhang, M. Xia, E. Gulbins, K. M. Boini, and P.-L. $\mathrm{Li}$, "Activation of Nlrp3 inflammasomes enhances macrophage lipid-deposition and migration: implication of a novel role of inflammasome in atherogenesis," PLoS ONE, vol. 9, no. 1, Article ID e87552, 2014.

[225] P. Duewell, H. Kono, K. J. Rayner et al., "NLRP3 inflammasomes are required for atherogenesis and activated by cholesterol crystals," Nature, vol. 464, no. 7293, pp. 1357-1361, 2010.

[226] L. Wang, P. Qu, J. Zhao, and Y. Chang, "NLRP3 and downstream cytokine expression elevated in the monocytes of patients with coronary artery disease," Archives of Medical Science, vol. 10, no. 4, pp. 791-800, 2014.

[227] T. Zhu, L. Zhang, S. Ling et al., "Scropolioside B inhibits IL$1 \beta$ and cytokines expression through NF- $\kappa \mathrm{B}$ and inflammasome NLRP3 pathways," Mediators of Inflammation, vol. 2014, Article ID 819053, 10 pages, 2014.

[228] B. Razani, C. Feng, T. Coleman et al., "Autophagy links inflammasomes to atherosclerotic progression," Cell Metabolism, vol. 15, no. 4, pp. 534-544, 2012.

[229] X. Liao, J. C. Sluimer, Y. Wang et al., "Macrophage autophagy plays a protective role in advanced atherosclerosis," Cell Metabolism, vol. 15, no. 4, pp. 545-553, 2012.

[230] X. Wang, L. Li, X. Niu et al., "mTOR enhances foam cell formation by suppressing the autophagy pathway," DNA and Cell Biology, vol. 33, no. 4, pp. 198-204, 2014.

[231] C. McCarthy, M. M. Duffy, D. Mooney et al., "IL-10 mediates the immunoregulatory response in conjugated linoleic acidinduced regression of atherosclerosis," The FASEB Journal, vol. 27, no. 2, pp. 499-510, 2013.

[232] D. Shiraishi, Y. Fujiwara, Y. Komohara, H. Mizuta, and M. Takeya, "Glucagon-like peptide-1 (GLP-1) induces M2 polarization of human macrophages via STAT3 activation," Biochemical and Biophysical Research Communications, vol. 425, no. 2, pp. 304-308, 2012.

[233] R. D. Singla, J. Wang, and D. K. Singla, "Regulation of notch 1 signaling in THP-1 cells enhances M2 macrophage differentiation," The American Journal of Physiology-Heart and Circulatory Physiology, vol. 307, no. 11, pp. H1634-H1642, 2014.

[234] K. Daub, D. Siegel-Axel, T. Schönberger et al., "Inhibition of foam cell formation using a soluble CD68-Fc fusion protein," Journal of Molecular Medicine, vol. 88, no. 9, pp. 909-920, 2010.

[235] Y. Yang, Y.-T. Lian, S.-Y. Huang, Y. Yang, L.-X. Cheng, and K. Liu, "GABA and topiramate inhibit the formation of human macrophage-derived foam cells by modulating cholesterolmetabolism-associated molecules," Cellular Physiology and Biochemistry, vol. 33, no. 4, pp. 1117-1129, 2014.

[236] A. C. Foks, A. H. Lichtman, and J. Kuiper, "Treating atherosclerosis with regulatory T cells," Arteriosclerosis, Thrombosis, and Vascular Biology, vol. 35, no. 2, pp. 280-287, 2015. 


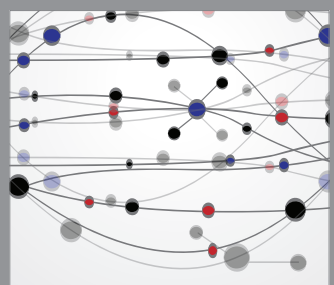

The Scientific World Journal
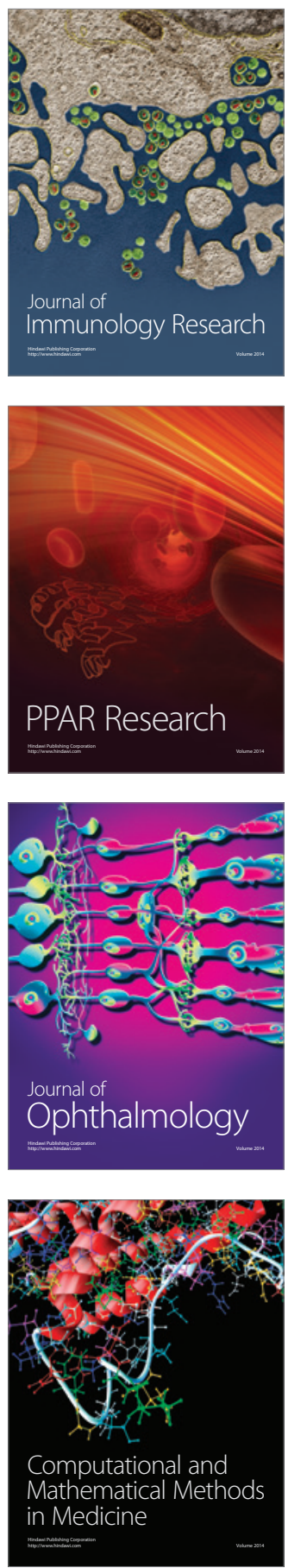

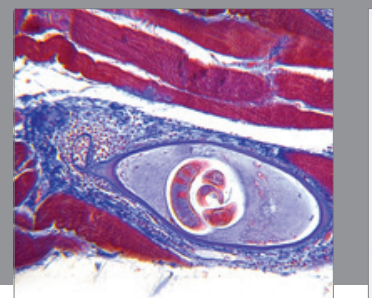

Gastroenterology

Research and Practice
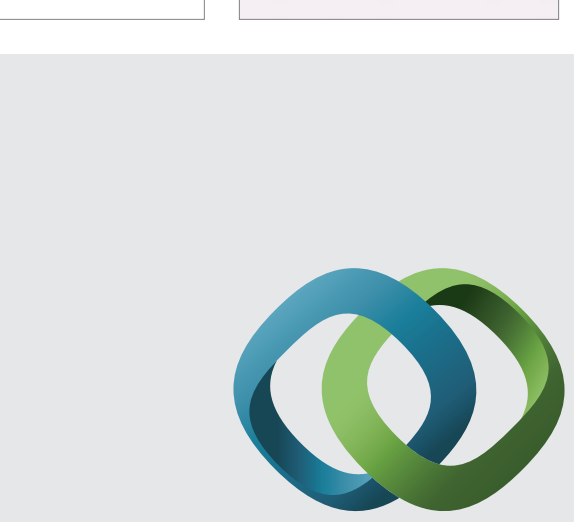

\section{Hindawi}

Submit your manuscripts at

http://www.hindawi.com
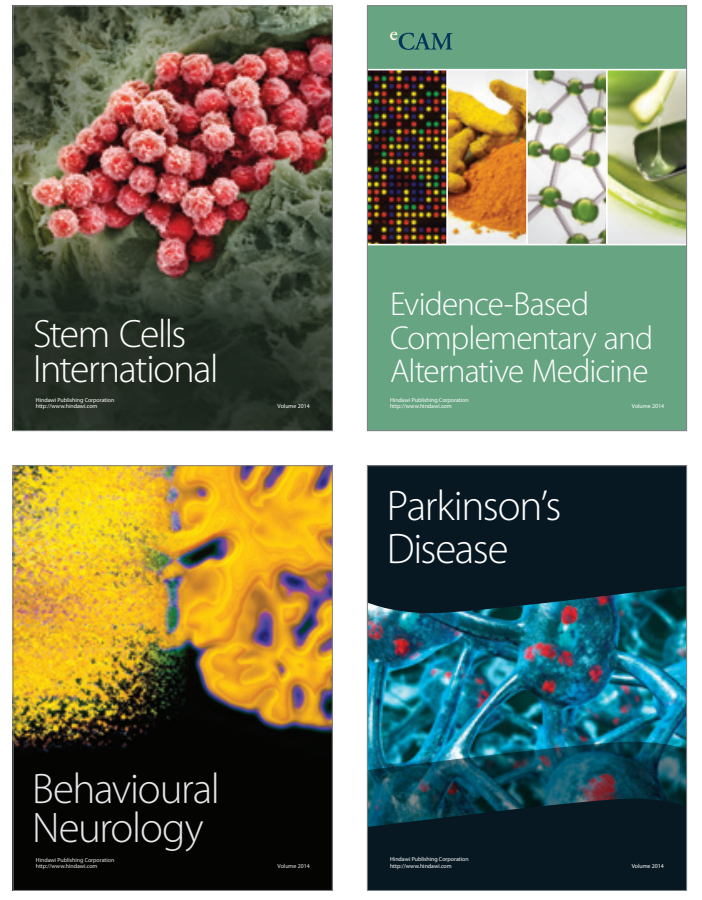
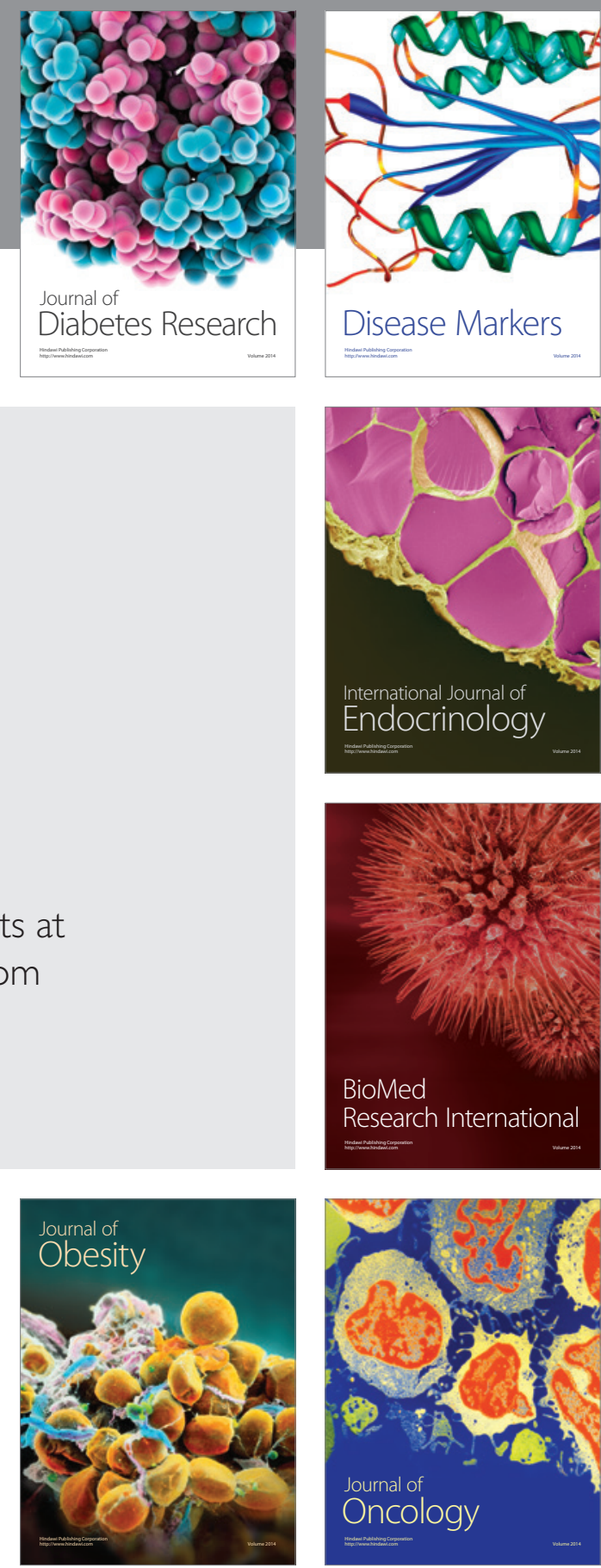

Disease Markers
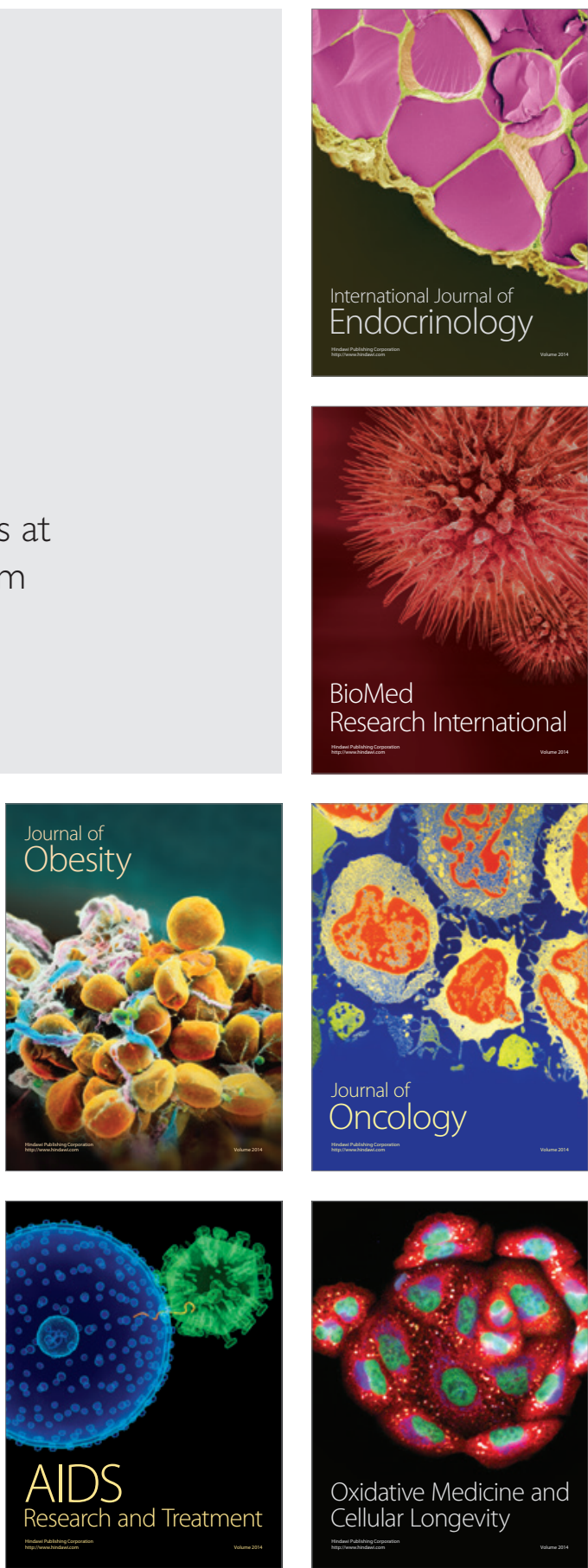